\title{
Mission Benefits of Gridded Ion and Hall Thruster Hybrid Propulsion Systems
}

\author{
John W. Dankanich* \\ Gray Research, Inc., Huntsville, AL, 35806 \\ Tara Polsgrove $e^{\dagger}$ \\ NASA - Marshall Space Flight Center, Huntsville, AL 35812
}

\begin{abstract}
The NASA In-Space Propulsion Technology (ISPT) Project Office has been developing the NEXT gridded ion thruster system and is planning to procure a low power Hall system. The new ion propulsion systems will join NSTAR as NASA's primary electric propulsion system options. Studies have been performed to show mission benefits of each of the stand alone systems. A hybrid ion propulsion system (IPS) can have the advantage of reduced cost, decreased flight time and greater science payload delivery over comparable homogeneous systems. This paper explores possible advantages of combining various thruster options for a single mission.
\end{abstract}

\section{Introduction}

Gridded ion thrusters, including the NASA Solar electric propulsion Technology Application Readiness

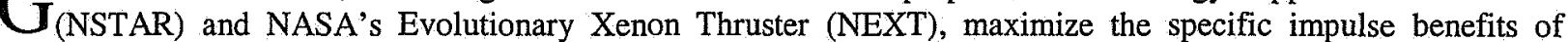
electric propulsion by thrusting for very long periods of time with high exhaust velocities. These gridded ion thrusters offer considerable mission benefits for high $\Delta \mathrm{V}$ missions. Hall thrusters have typically been flown for station keeping due to their ability to operate efficiently at very low powers, but lack the lifetime necessary for primary propulsion on most science missions. With the advances of NASA's HiVHAC thruster program, Hall thrusters may soon join NSTAR as a NASA primary propulsion option for science missions.

Gridded ion thrusters on large $\Delta \mathrm{V}$ missions can offer a significant benefit over Hall thrusters, while missions thrusting near gravity wells or operating for large periods of time at low throttle conditions may favor the Hall systems. An ideal thruster would be able to throttle efficiently to low power and operate at moderate specific impulses with high thrust-to-power ratios, while maintaining acceptable lifetimes. Hall thrusters can efficiently provide higher thrust-to-power ratios than their gridded ion counterparts, but at lower specific impulses. Unfortunately state-of-the-art (SOA) Hall thrusters have not shown the necessary life required for primary propulsion. Gridded ion thrusters have significantly longer lifetime than comparable Hall systems, operate both at higher specific impulses and with higher peak efficiencies, but have low thrust-to-power capabilities using SOA molybdenum grid materials. Until a single thruster is developed that can operate over large ranges in specific impulse and thrust, it is intuitive that several missions can benefit from a hybrid system that can use the advantages of both systems in a symbiotic operation. There have been attempts to operate gridded ion thrusters at higher thrustto-power ratios ${ }^{1}$ and Hall thrusters at higher specific impulses ${ }^{2}$; both cases result in rapid erosion of critical components, and require either advancement in materials or technologies. Finally, hybrid thruster systems have been proposed for very large nuclear electric propulsion (NEP) missions with gridded ion thrusters for very high specific impulse interplanetary transfers and Hall thrusters for higher thrust maneuvers and ACS control. ${ }^{3}$

\section{Thruster Background}

Thrusters under consideration for this study were limited to NASA's NSTAR, NEXT, and HiVHAC thrusters with the addition of the commercial BPT- 4000 Hall thruster. Table 1 shows a comparison of thruster metrics. The actual performance of the thrusters can operate over a large range of operating characteristics, but the performance in the table is the current baseline operation used within this study. Also, only the NSTAR throughput is based on a completed life test, the HiVHAC and NEXT thruster lifetimes are development objectives, and the

\footnotetext{
* Aerospace Engineer, In-Space Propulsion, John.Dankanich@nasa.gov, Member AIAA.

${ }^{\dagger}$ Aerospace Engineer, Advanced Concepts, VP11, Tara.Polsgrove@nasa.gov, Member AIAA
} 
BPT-4000 lifetime is the current qualified throughput with additional testing on-going. Figure 1 also shows the throttle table performance of the various thrusters. These thrusters were chosen as those currently of interest to meet NASA's science mission needs. They have on-going NASA funding ${ }^{4}$ towards the improvement, development, or qualification testing of these systems. Several Hall thrusters are already available in addition to the Boeing XIPS gridded ion thrusters, but they have yet to be evaluated to meet science mission requirements.

Table 1: Thruster characteristics.

\begin{tabular}{|c|c|c|c|c|}
\cline { 2 - 5 } \multicolumn{1}{c|}{} & NSTAR & NEXT & HiVHAC & BPT-4000 \\
\hline Max. Input Power (kW) & 2.3 & 6.9 & 3.6 & 4.5 \\
\hline Throttle Range & $4.8: 1$ & $12.6: 1$ & $12: 1$ & $4: 1$ \\
\hline Specific Impulse (s) & 3,100 & 4,170 & 2750 & 1983 \\
\hline Thrust (mN) & 94 & 236.4 & 150.7 & 282 \\
\hline Efficiency at Full Power & 0.6 & 0.7 & 0.57 & 0.57 \\
\hline Thrust-to-Power (mN/kW) & 40 & 34 & 41.9 & 63 \\
\hline Throughput (kg) & 157 & $>300^{*}$ & $>150^{*}$ & $>172^{*}$ \\
\hline Specific Mass (kg/kW) & 3.6 & 1.9 & 2.4 & 2.73 \\
\hline
\end{tabular}
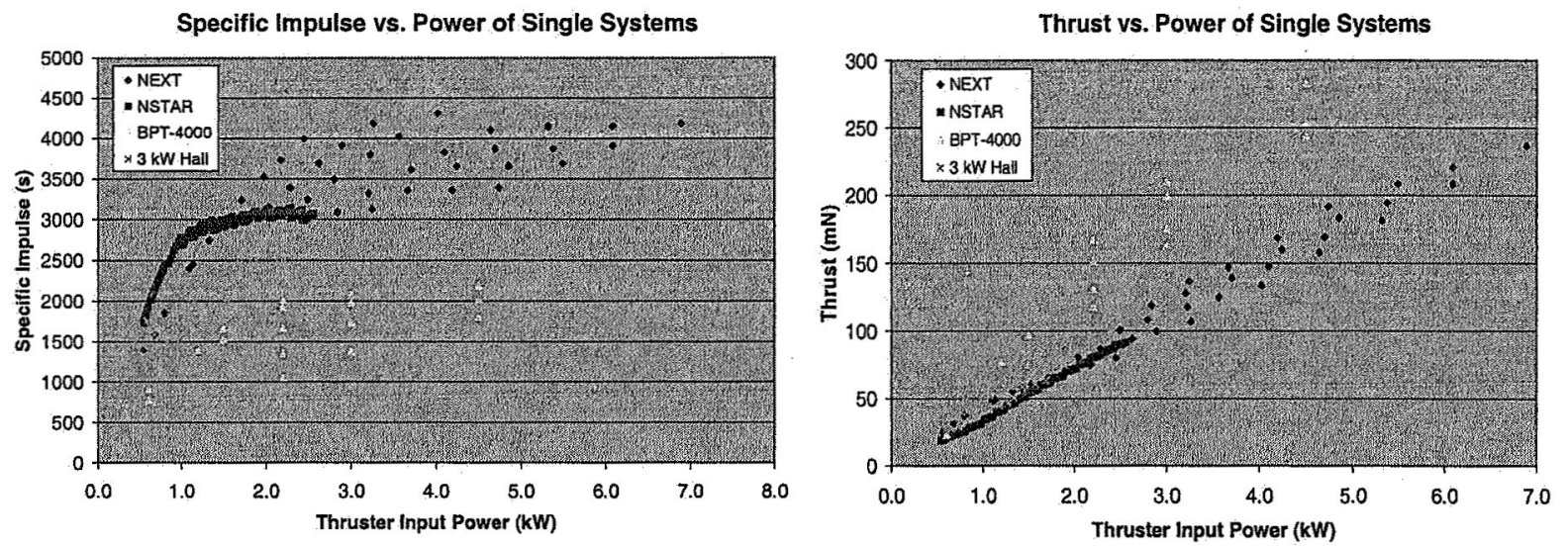

Figure 1: Specific impulse (left) and thrust (right) as a function of power of baseline thruster performance.

\section{A. NSTAR}

In the early 1990s, NASA's GRC and JPL partnered for the NSTAR program to develop an ion propulsion system for primary propulsion on deep space missions. The NSTAR thruster was successfully demonstrated on the New Millennium Program Deep Space 1. The NSTAR thruster is currently planned to fly on Dawn as the first NASA science mission to use primary electric propulsion.

\section{B. NEXT}

Under a cycle zero NRA solicited by NASA's ISPT Project, the NEXT thruster system development was awarded to a team led by NASA's GRC and including JPL, Aerojet, Boeing EDD (Now L3-Com) and CSU for an electric propulsion option for Flagship class missions. The NEXT thruster offers an evolutionary advance in technology over the SOA NSTAR thruster. The NEXT thruster operates with a higher maximum power, thrust, specific impulse and efficiency. The NEXT thruster is also expected to have a total impulse capability several factors greater than the existing NSTAR engine.

\section{HiVHAC}

Under a cycle two ISP NRA, the High Voltage Hall Accelerator (HiVHAC) thruster development which was awarded to NASA's GRC teamed with Aerojet, JPL and the University of Michigan for a 6-8 kW Hall thruster with moderate Isp for Flagship class missions. After the focus of ISPT project turned from large missions to smaller 
Discovery and New Frontiers missions, the HiVHAC program was re-vectored to develop a smaller HiVHAC thruster with a Pmax of approximately $3 \mathrm{~kW}$ specifically to increase low power performance and reduce cost for Discovery class electric propulsion missions. The HiVHAC thruster has a large throttle range as well as a large specific impulse range.

Currently, the HiVHAC program is continuing as a high-risk/high-payoff in-house thruster development at GRC. The effort has a parallel development approach for a low cost $3.75 \mathrm{~kW}$ thruster with a lifetime goal of 9,000 hours and an extended life, in-situ channel replacement, $3.75 \mathrm{~kW}$ thruster with a lifetime goal of greater than 30,000 hours. Performance testing of the two thrusters will occur in the summer of 2006.

\section{BPT -4000}

Aerojet has recently finished the qualification tests of the BPT -4000 Hall thruster. The BPT- 4000 is a 4.5 $\mathrm{kW}$ multi-mode Hall thruster development effort part of an Aerojet and Lockheed Martin Space Systems Company funded to develop a Hall IPS for use on geosynchronous satellites. The thruster is designed to operate between 3 $\mathrm{kW}$ and $4.5 \mathrm{~kW}$ at discharge voltages between 300 volts and 400 volts. The thruster will operate at lower voltage and higher thrust-to-power for orbit raising maneuvers, and then at higher voltage for higher specific impulse during station keeping. ${ }^{5}$

The in-space propulsion project office has taken the opportunity to extend the life test of the BPT- 4000 to demonstrate a larger throughput capability and to assess the performance of the thruster at low power operation. Qualification life testing processed approximately $260 \mathrm{~kg}$ of propellant for a flight operational throughput capability of $157 \mathrm{~kg}$. The life test is currently continuing with the hopes of demonstrating over $400 \mathrm{~kg}$ or a mission throughput capability of $285 \mathrm{~kg}$ of propellant.

\section{Thrust-to-Power Effect on Mission Performance}

There is a misconception outside the low-thrust community that a high specific impulse is always better. This belief is founded from the Tsiolkovsky's rocket equation:

$$
\frac{m_{0}}{m_{1}}=e^{\frac{\Delta V}{g l s p}}
$$

and its general application for high thrust and high jet power, chemical propulsion systems where an increase from 400 s to 1000 s in Isp can have phenomenal mission impacts. In high thrust applications, the correlation between increases in Isp with performance is observed. The exceptions to the norm lie in the makeup of the $\Delta \mathrm{V}$ term and real world losses. An obvious example is gravity losses associated with ascent and decent. A launch vehicle with a thrust-to-weight ratio of $\leq 1$ will consume all of its propellant without any change in velocity.

There are analogous scenarios in orbital mechanics such as plane changes:

$$
\Delta V=2 V i \sin (\theta / 2)
$$

Because the velocity of a satellite in an elliptical orbit is slowest at apoapsis, there may be an advantage to perform high thrust plane changes at the apoapsis of an elliptical orbit compared to a low thrust, higher specific impulse, maneuver that would take place over a higher average velocity leading to a higher $\Delta V$ requirement.

The performance of electric propulsion thrusters are limited by the available power. For a constant power, thrust and specific impulse are inversely proportional.
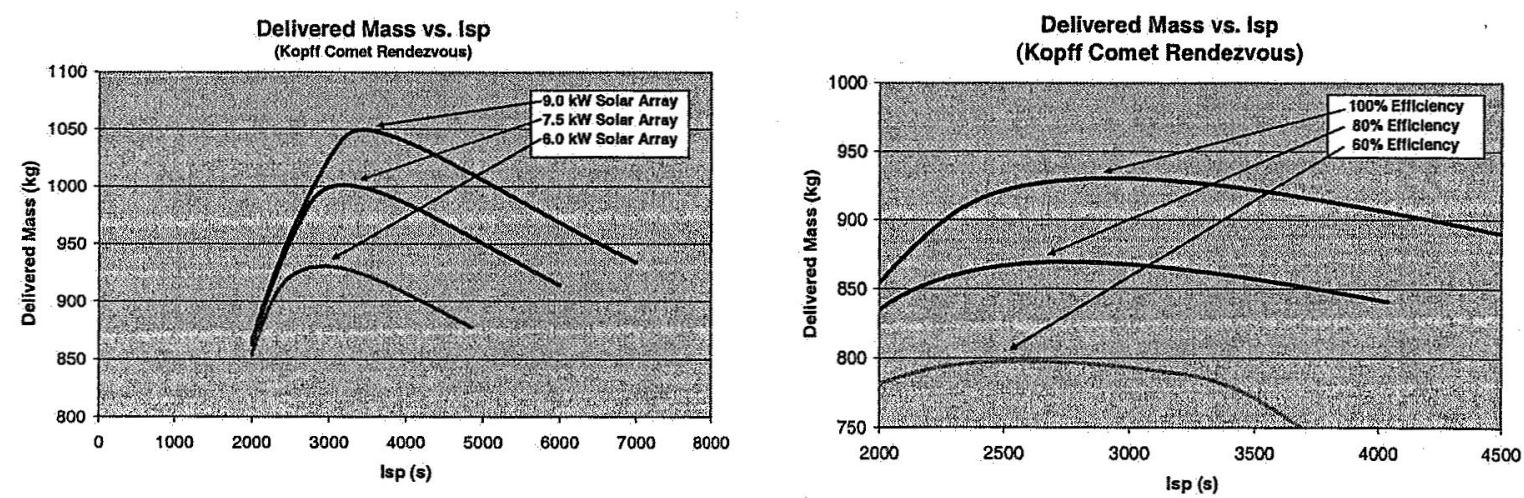

Figure 2: Optimized specific impulse for example comet rendezvous mission. 


$$
P=\frac{\eta g\left(F I_{s p}\right)}{2}
$$

Because of the relationship between thrust and specific impulse, a mission profile that prefers a higher thrust-to-power ratio will optimize to a lower specific impulse. It is also worth noting that in general both griddedion and Hall thrusters operate at higher efficiencies at high specific impulses.

While the metric used for IPS comparison is thrust-to-power, the true metric which determines performance is the thrust-to-weight capability of the spacecraft. Thrust-to-weight spacecraft requirements may not always be due to optimal specific impulse, but are often imposed by other mission consideration such as timing of target alignments, practical mission durations, etc. It is common practice to improve the thrust-to-weight of a spacecraft by simply adding thrusters. An extreme example is the Jupiter Icy Moons Orbiter mission that proposed over 20 gridded ion engines to decrease the time spent maneuvering in the high radiation regions around Jupiter. ${ }^{6}$ There are, however; missions that may yield better performance with a combination of fewer Hall and gridded ion thrusters rather than excessive homogenous thrusters.

To be complete, there are also numerous missions that will optimize to very high specific impulses and there are methods of modifying mission approaches to optimize to lower thrust-to-power ratios. For example, a Nereus sample return mission using a high entry velocity capsule optimizes at a specific impulse of over 7,000 seconds, while the same mission returning the sample to the International Space Station optimizes to a specific impulse under 3,000 seconds; and allowing the return vehicle to take an additional trip around the sun with an earth swing by will again increase the desired specific impulse. Specific impulse can also be very dependent on the power subsystem. An 80 metric ton Mars roundtrip mission can optimize anywhere from 2,000 seconds to 14,000 seconds as the power system alpha varies from $100 \mathrm{~W} / \mathrm{kg}$ to $500 \mathrm{~W} / \mathrm{kg}$ respectively.

\section{Comet Surface Sample Return}

NASA's New Frontiers program includes missions for a Venus In-Situ Explorer, Lunar South Pole Sample Return, and a Comet Surface Sample Return (CSSR). The CSSR mission is most applicable to electric propulsion. CSSR missions have been studied for Temple 1 and the New Frontiers design reference mission (DRM) to the comet Wirtenan. Some studies have indicated that a CSSR mission using chemical propulsion may not be able to return adequate science using existing chemical systems and launch vehicles. ${ }^{8}$ The benefits to higher thrust-to-weight systems have been documented for homogenous systems, in some cases, enabling the mission. 9

The characteristics of the CSSR missions include a direct trajectory to the comet, a surface

Wirtenan CSSR Delivered Mass vs. Isp

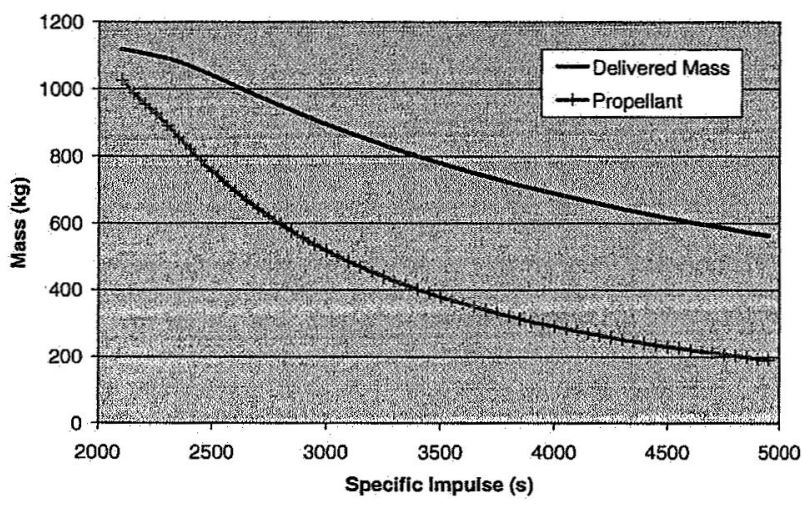

Figure 4: Delivered mass and propellant mass dependency on specific impulse.

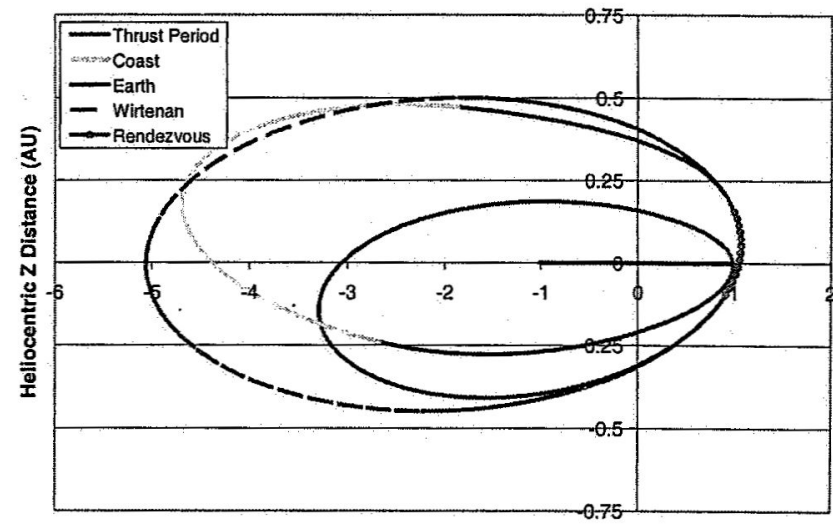

Heliocentric Y Distance (AU)

Figure 3: Example CSSR mission trajectory.

stay time of sixty days, and then a direct return to Earth. One of the propulsion challenges of a CSSR mission is meeting entry velocity requirements. Based on previous missions and analysis, the maximum entry velocity of the return capsule is assumed to be $13 \mathrm{~km} / \mathrm{s}$. Figure 3 illustrates the Y-Z plane of the CSSR mission profile. In order to meet the entry velocity requirements, the mission requires a significant plane change. The mission also requires a relatively large $\Delta \mathrm{V}$ in a short period of time to meet the velocity and alignment requirements without additional revolutions around the sun. Because of the need for relatively fast $\Delta V s$, a high thrust-to-weight ratio is required. Figure 4 illustrates the delivered mass capability as a function of specific impulse. The performance clearly shows that one can 
either deliver a smaller payload or use a lower specific impulse thruster. The performance curve also clearly indicates that even though the mission propellant requirement increases significantly with decreased specific impulse, it does not correlate to decreased delivered mass. Note that this does not include the IPS mass; additional thrusters for thrust-to-weight ratios or propellant throughput requirements will limit the mission payload capability.

\section{Lifetime Effect on Mission Performance}

The gridded ion and Hall thrusters also have considerably different lifetime capabilities at comparable specific impulses. The gridded ion thrusters operate at very high voltages which correlate to high exhaust velocities. For comparable power levels and exhaust velocities, the gridded ion thrusters have demonstrated considerably longer lifetimes than Hall thrusters. Hall thrusters on the other hand, have an increasing channel erosion rate with voltage. Operating a Hall thruster at $1 \mathrm{kV}$, below both NSTAR and NEXT; would have lifetimes several factors less than their gridded ion counterparts. The lifetime capability of a thruster has a large impact on mission planning and performance.

\section{A. CSSR}

From the previous discussion of the CSSR mission, the BPT-4000 thruster can operate at the optimal thrust-to-power ratio for the mission. Unfortunately, the demonstrated throughput is still far below that required for the mission. For the optimal Isp, a BPT-4000 IPS would require seven thrusters for lifetime as currently qualified; the ongoing extension has the possibility to lower the number to four. There is no advantage to sending additional mass to the comet, if all of the additional mass is in the ion propulsion system. Also, it is not likely that a $7+1$ thruster configuration can be qualified and flown within the cost cap for the mission. Flying fewer thrusters will have the benefit of both a reduced IPS mass and cost.

\section{B. Dawn}

Dawn is the ninth mission selected in the Discovery Program with a mission to explore two main belt asteroids, Vesta and Ceres. ${ }^{10}$ It is the first mission ever to enter orbit around one body and then leave to go into orbit around a secondary body. The IPS will deliver a total $\Delta \mathrm{V}$ of $11 \mathrm{~km} / \mathrm{s}$; more than double the $\Delta \mathrm{V}$ of any previous onboard propulsion system.

The Dawn mission is unique in many ways. It was considered too difficult to orbit even one main belt asteroid using chemical propulsion and still fit within the Discovery mission cost cap. Dawn could possibly bring in a new era of science missions that travel to multiple destinations. One of the undesired features of the Dawn IPS is the need for additional thruster solely for the purpose of propellant throughput capability. The additional thruster for throughput, with cross-strapping and integration, led to unexpected costs. It was later recommended that future ion propulsion systems operate in single string configurations for reduced mission costs. ${ }^{11}$ It was also recommended that additional thrusters should not be flown solely for life, and that investments should be made for longer lifetime capable thrusters.

There has already been considerable investment for gridded ion thrusters with increased capability over NSTAR. The ISPT refocus studies indicated that a single NEXT thruster could perform the Dawn mission with a $5 \%$ increase in delivered mass. ${ }^{12}$ In a relative sense, that would more than double the mass available for science. Another finding of the refocus studies was that the HiVHAC Hall thruster could also outperform the NSTAR engine by $14 \%$. Again, the limit of the Hall thruster is lifetime; because the mission would require almost $540 \mathrm{~kg}$ of xenon at the Hall thruster's lower specific impulse compared to NSTAR's $385 \mathrm{~kg}$ requirement. It is another example of a higher thrust-to-power ratio, lower

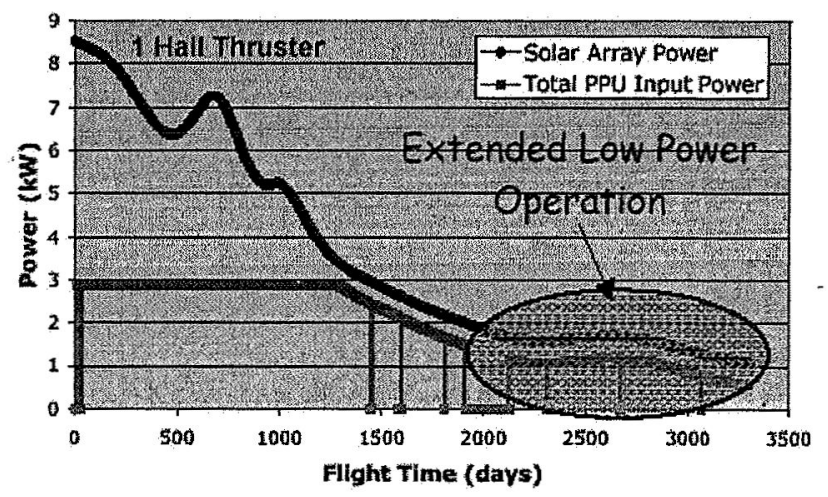

Figure 5: Hall Throttle Profile for Dawn Mission. 
specific impulse, thruster that can outperform a more efficient thruster. Unfortunately, due to the qualification standard of $150 \%$, the $540 \mathrm{~kg}$ of propellant would require the actual $3 \mathrm{~kW}$ Hall thruster throughput capability to be over $800 \mathrm{~kg}$, close to an order of magnitude greater than SOA for an $2 ; 800 \mathrm{~s} \mathrm{Xe}$ thruster!

There has been concern that the mass and cost of the NEXT IPS is too high for Discovery class missions. While this may not be a legitimate concern, the NEXT PPU alone is expected to be more than double the cost and up to four times the mass of a $3 \mathrm{~kW}$ Hall PPU. Because the HiVHAC thruster can outperform the NEXT thruster, there is a possibility for the HiVHAC thruster to serve as the spare for a NEXT engine. One can envision a set of multiple destination missions can be completed with a single NEXT thruster, and in the case of a failure; the spare Hall thruster can reach the primary destination to meet minimum science objectives.

There has also been a recent push within the low-thrust community to gain acceptance into lifetime throughput capability by analysis. ${ }^{13}$. A general characteristic of outbound science missions is a short period of relatively high power operation followed by long periods of low power operation. The typical power drop-off is inherent to solar electric propulsion due to the $1 / \mathrm{r}^{2}$ falloff of available power. Throughput capabilities are currently based on demonstration tests. Throughput demonstration tests can run for several years and there is a desire to operate the test at full power for as long as possible to process as much propellant in the shortest amount of time. Preliminary analysis has shown for both gridded ion and Hall thrusters that expected lifetimes based on actual mission profiles can be several factors greater than that at full power. Running the thrusters in a de-rated state for the majority of the mission could lead to dramatic increases in lifetime and therefore mission capability. This scenario would have tremendous science return for low-cost Discovery class missions.

\section{Power Profile Effect on Mission}

As mentioned previously, both inbound and outbound missions show a large change in available power throughout the course of a mission. It has been repeatedly shown that the ion propulsion system that can best utilize the available power will have the highest performance. The benefit of a hybrid system can be two-fold for a mission that spans a large power range. A thruster typically operates very efficiently at full power, but generally shows a sharp drop in performance as the thruster is operated near its lower throttle limit. Using two different thrusters can both extend the throttle capability of the IPS, and the IPS can be operating in such a way to provide a higher efficiency throttle profile than can be achieved with a single system. Figure 6 shows an example of a possible homogenous vs. hybrid throttle profile. The example hybrid performance curve can operate at the

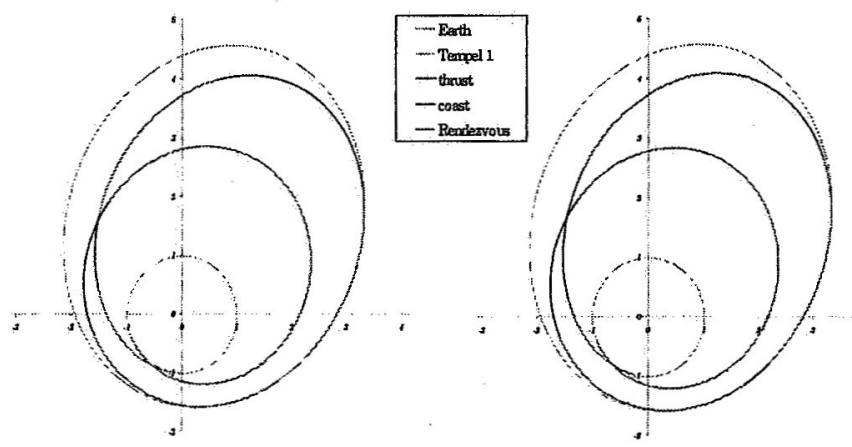

Figure 7: Temple 1 CSSR mission for NEXT (left) and lower Pmin (right).

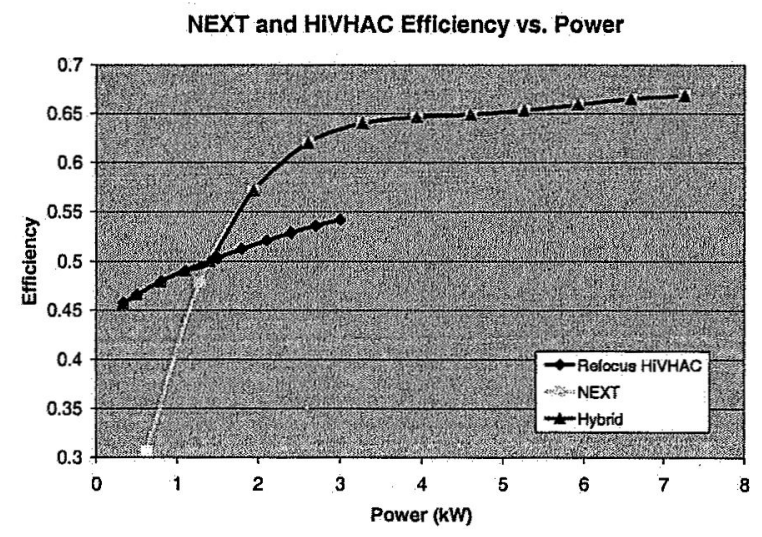

Figure 6: Example NEXT, HiVHAC, and hybrid thruster efficiency versus power comparison.

lower operating power and high efficiency of the Hall thruster and maintain the higher power high efficiency of the NEXT thruster. An additional benefit of the hybrid example in figure 6 is that the Hall thruster shown is only operating in a de-rated mode, and should therefore have increase in expected lifetime. Figure 7: shows the thrust profile effect of reducing the minimum operating power. The CSSR mission to Temple 1 on the right can take advantage of higher $\mathrm{AU}$ thrusting and shows a performance increase of $7 \%$ and a $\Delta \mathrm{V}$ reduction of $\sim 400 \mathrm{~m} / \mathrm{s}$. Running the NEXT thruster efficiently at 200 watts is not feasible, while the added hybrid capability can perform high $\mathrm{AU}$ maneuvers and possibly lower the solar array end-of-life requirements. Both Hall and 
NEXT thrusters could also be run simultaneously up to $10 \mathrm{~kW}$; however, increasing the maximum power by combining thrusters is not unique to hybrid systems.

\section{Escape Trajectory Assist}

There have also been studies that have shown an advantage to using electric propulsion from LEO or negative C3 elliptical orbits to boost a payload to escape. ${ }^{14}$ The use of electric propulsion within the gravity well of earth generally optimizes to a specific impulse near 2,200 seconds. There is an advantage to a stage approach that could use a lower specific impulse thruster for an escape assist stage prior to the utilization of a higher specific impulse thruster for challenging missions preferring the higher propellant efficiency. The 2,200 second escape boost stage is best performed using Hall thrusters similar to the BPT-4000, but again will not likely have the throughput capability to perform an additional $\Delta \mathrm{V} \sim$ $10 \mathrm{~km} / \mathrm{s}$ for the interplanetary portion of the mission. Also, for large class missions such as flagship missions to Titan, the optimal specific impulse for the interplanetary $\Delta \mathrm{V}$ is near 4,000 s. A hybrid system with a Hall for GTO assist and a higher specific impulse gridded ion thruster should not only provide additional delivered mass capability, but also has mission flexibility and redundancy. For example, missed thrust periods

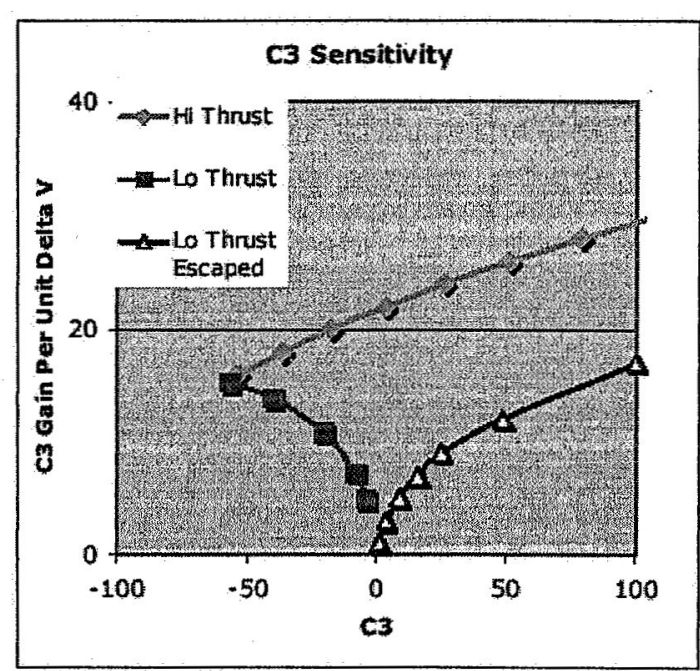

Figure 8: SEP Leverage vs. High Thrust. ${ }^{12}$ can lead to significant increases in burn times on a very high specific impulse thruster, while the Hall stage could be used for a short duration $\Delta \mathrm{V}$; provided propellant was available. There are significant mission duration penalties for used an EP stage.

\section{Hybrid System Comparison}

There are implications of using a Hybrid thruster system that are not addressed. For example, there is likely to be a cost benefit in flying a multi-thruster homogenous system; spares can be interchanged, interfaces will be the same, the vendor will be the same, etc. Spare thrusters carried on the spacecraft may also have a negative impact on the IPS mass.
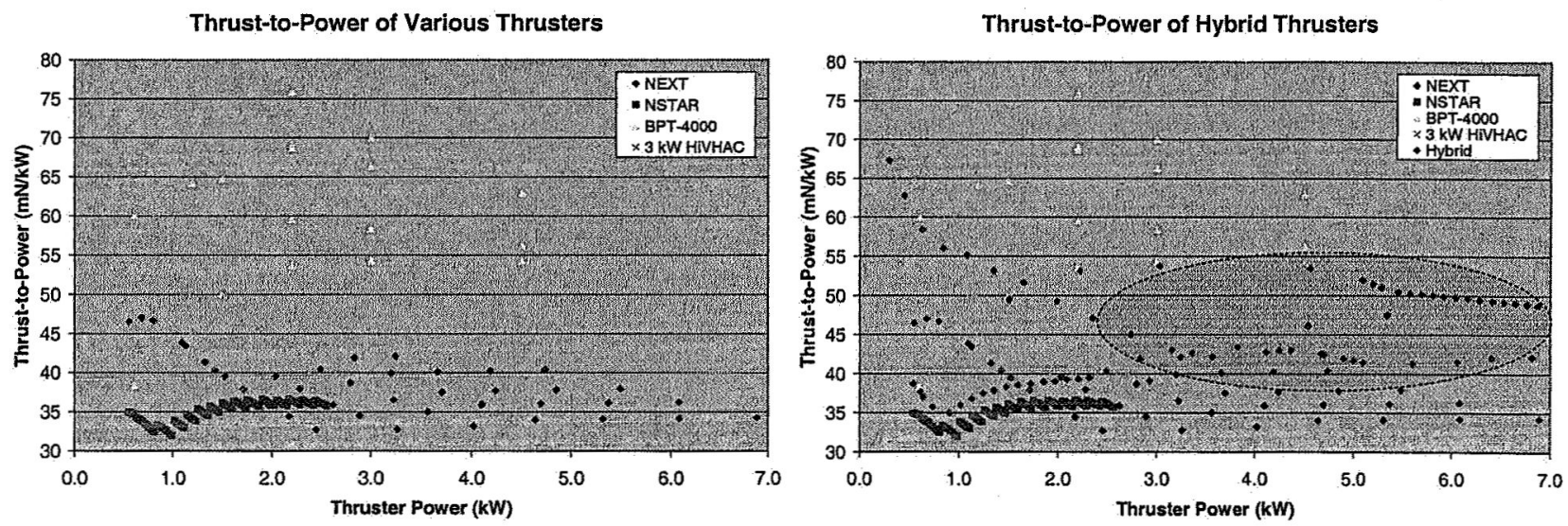

Figure 9: Comparison of thrust-to-power ratios of homogenous and hybrid thrusters.

The advantage for a hybrid system is the ability to both operate at a higher thrust-to-power ratio at higher power and to demonstrate longer life. Figure 9 shows the comparison of homogenous to hybrid thruster combinations. The figure does not show all of the operating points, but does show that higher power higher thrustto-power ratios can be achieved with hybrid systems. Not to be misleading, the HiVHAC thruster does behave very similar to a hybrid IPS because of its ability to throttle specific impulse with power. It should be noted that the HiVHAC cannot maintain the high thrust-to-power ratios at full power due to plasma density constraints; however, 
using a combination of several HiVHAC thrusters will create flexibility and is expected to perform well against a hybrid IPS.

\section{A. Assumptions}

For comparison of systems, it was assumed that all thrusters will operate in a single string configuration with an independent power processing unit (PPU). The mass estimates and IPS assumptions are listed in table 2. There is also a mass contingency applied of $30 \%$ for breadboard and engineering model hardware and $10 \%$ for qualified hardware. For hybrid systems of qualified and non-qualified hardware, the contingency was applied at the component level, not as a complete IPS. The feed system for both NSTAR and NEXT was also assumed to be the NEXT feed system. Only the BPT-4000 thruster and PPU were assumed to be qualified hardware for science missions, additional subsystems are estimated. Finally, the mass of the PPU/DCIU for NEXT and NSTAR is assumed to be the current best estimate of the PPU with an additional $2 \mathrm{~kg}$ included for digital control interface unit (DCIU) functionality hardware to be included within the PPU.

Table 2: Mass estimates and IPS assumptions for mass calculations.

\begin{tabular}{|l|c|c|c|c|}
\cline { 2 - 5 } \multicolumn{1}{c|}{} & NSTAR & NEXT & HIVHAC & BPT-4000 \\
\hline Mass per Thruster (kg) & 8.2 & 12.7 & 9 & 12.3 \\
\hline Mass per PPU/DCIU (kg) & 15.9 & 36.6 & 10.5 & 12.5 \\
\hline Mass per Gimbal (kg) & 5.25 & 5.98 & 5 & 6 \\
\hline Fixed Mass XFS (kg) & 2.2 & 2.2 & 4 & 4 \\
\hline XFS Mass per Thruster (kg) & 4.1 & 4.1 & 1 & 1 \\
\hline Nav. \& Traj. Errors & $5.0 \%$ & $5.0 \%$ & $5.0 \%$ & $5.0 \%$ \\
\hline Residuals & $3.6 \%$ & $3.6 \%$ & $3.6 \%$ & $3.6 \%$ \\
\hline Tank Fraction & $4.50 \%$ & $4.50 \%$ & $4.50 \%$ & $4.50 \%$ \\
\hline
\end{tabular}

\section{B. Results}

The comet surface sample return from the comet Wirtenan was compared for homogenous NEXT thrusters, both high-thrust and high-Isp, the HiVHAC SOA thruster, NSTAR, in addition to hybrid systems that included either the Hall or gridded ion thruster incrementally, or a combined throttle curve that operated both thrusters simultaneously. The homogeneous NSTAR thruster is the lowest performer of the various ion propulsion systems, the homogenous HiVHAC thruster actually performs the best in terms of delivered mass, as expected based on the optimal specific impulse but required $775 \mathrm{~kg}$ of propellant throughput; based on SOA expected lifetimes of a $3 \mathrm{~kW}$ thrusters that would require at least six thrusters. The NEXT homogenous systems deliver more than the NSTAR, but less than the Hall systems, and as expected; the high-thrust NEXT outperforms the high-Isp NEXT throttle curve. The hybrid systems run either individually or concurrently operating in a $2+2$ configuration and have more than a $20 \%$ improvement over all but the $5+1$ Hall configuration.

\section{Relative Performance of IPS}

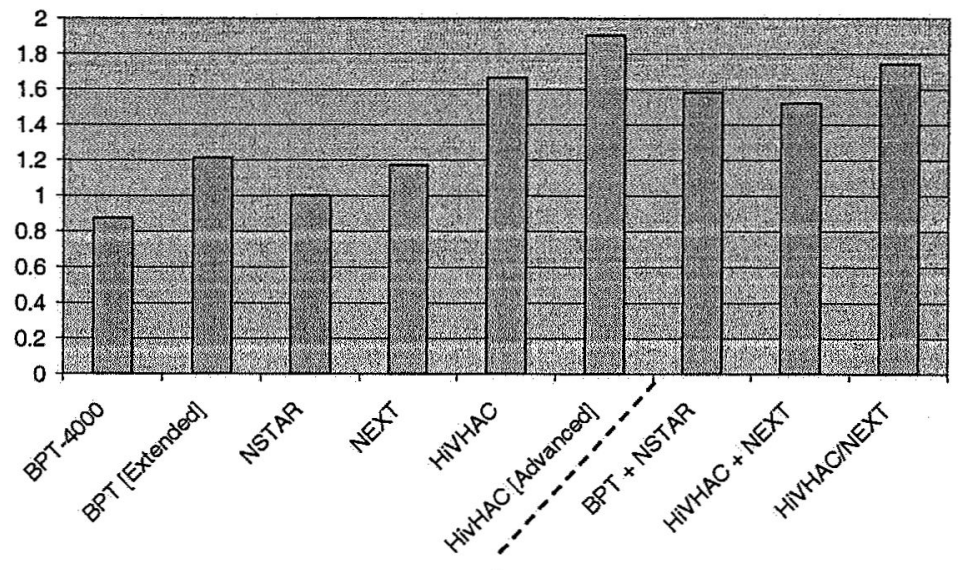

Figure 10: Relative comparison of homogenous and hybrid IPS performance. 
Table 3: Homogenous IPS performance comparison.

\begin{tabular}{|c|c|c|c|c|c|c|}
\hline Thruster & NEXT & HIVHAC & $\begin{array}{c}\text { HIVHAC } \\
\text { (Advanced) }\end{array}$ & NSTAR & BPT-4000 & $\begin{array}{l}\text { BPT-40UU } \\
\text { [Extended] }\end{array}$ \\
\hline \# of Operating Thrusters & 2 & 3 & 3 & 3 & 2 & 2 \\
\hline \# of Spare Thrusters for Life & 0 & 3 & 0 & 0 & 6 & 2 \\
\hline \# of Spare Thrusters for Redundanc & 1 & 1 & 1 & 0 & 1 & 1 \\
\hline Total Thrusters & $3(2+1)$ & $7(3+4)$ & $4(3+1)$ & $4(3+1)$ & $9(2+7)$ & $5(2+3)$ \\
\hline Array Power (kW @ 1 AU B.O.L.) & 10 & 10 & 10 & 10 & 10 & 10 \\
\hline Launch Vehicle & Atlas 401 & Atlas 401 & Atlas 401 & Atlas 401 & Atlas 401 & Atlas 401 \\
\hline Trip Time (yrs) & 8 & 8 & 8 & 8 & 8 & 8 \\
\hline $\mathrm{C3}\left(\mathrm{km}^{2} / \mathrm{s}^{2}\right)$ & 38.64 & 28.12 & 28.12 & 48.2 & 24.7 & 24.7 \\
\hline $\mathrm{mo}(\mathrm{kg})$ & 1511.4 & 1936.7 & 1936.7 & 1168 & 2094.2 & 2094.2 \\
\hline Mp - Required Throughput (kg) & 525.9 & 775.1 & 775.1 & 375.2 & 1124.9 & 1124.9 \\
\hline Throughput Contingency (kg) & 42.6 & 62.8 & 62.8 & 62.8 & 91.1 & 91.1 \\
\hline Total Propellant (kg) & 568.5 & 837.9 & 837.9 & 438 & 1216 & 1216 \\
\hline Tank Mass (kg) & 25.6 & 37.7 & 37.7 & 19.7 & 54.7 & 54.7 \\
\hline IPS Drymass (kg) & 257.1 & 220.2 & 143.7 & 155.7 & 344.9 & 217.7 \\
\hline Drymass Contingency (kg) & 77.1 & 66.1 & 43.1 & 36 & 48 & 34.5 \\
\hline Total Wet Mass (kg) & 902.7 & 1124.2 & 1024.7 & 629.7 & 1608.9 & 1468.2 \\
\hline Mass Left at Comet (kg) & 125 & 125 & 125 & 125 & 125 & 125 \\
\hline Net Delivered Mass $(\mathrm{kg})^{* *}$ & 483.7 & 687.5 & 787 & 413.3 & 360.3 & 501 \\
\hline
\end{tabular}

Table 4: Hybrid IPS performance comparison.

\begin{tabular}{|l|c|c|c|}
\hline \multicolumn{1}{|c|}{ Thruster } & HiV / NEXT & HiV + NEXT & NSTAR+BPT \\
\hline \# of Operating Thrusters & $2(1,1)$ & $2(1,1)$ & $2(1,1)$ \\
\hline \# of Spare Thrusters for Life & $1^{*}$ & $1^{*}$ & $1^{*}$ \\
\hline \# of Spare Thrusters for Redundanc & $1^{*}$ & $1^{*}$ & $1^{*}$ \\
\hline Total Thrusters & $4(2+2)$ & $4(2+2)$ & $4(2+2)$ \\
\hline Array Power (kW @ 1 AU B.O.L.) & 10 & 10 & 10 \\
\hline Launch Vehicle & Atlas 401 & Atlas 401 & Atlas 401 \\
\hline Trip Time (yrs) & 8.1 & 8 & 8 \\
\hline C3 (km (s) $^{2}$ ) & 34.83 & 37.62 & 37 \\
\hline m0 (kg) & 1659.7 & 1550.7 & 1575.6 \\
\hline Mp - Required Throughput (kg) & 517.1 & 500.3 & 557.2 \\
\hline Throughput Contingency (kg) & 41.9 & 40.5 & 45.1 \\
\hline Total Propellant (kg) & 559 & 540.8 & 602.3 \\
\hline Tank Mass (kg) & 25.2 & 24.3 & 27.1 \\
\hline IPS Drymass (kg) & 197.2 & 197.2 & 159.8 \\
\hline Drymass Contingency (kg) & 59.1 & 59.1 & 34.7 \\
\hline Total Wet Mass (kg) & 815.3 & 797.1 & 796.8 \\
\hline Mass Left at Comet (kg) & 125 & 125 & 125 \\
\hline Net Delivered Mass (kg) & 719.4 & 628.6 & 653.8 \\
\hline
\end{tabular}

It has not been evaluated as to how many thrusters can feasibly be placed on the spacecraft. Flying several thrusters with multiple operating simultaneously may also require additional qualification testing and analysis. . The cost of spacecraft integration will increase with complexity. Therefore, fewer thrusters would most likely be preferred without a substantial or mission enabling performance gain. A spacecraft integration penalty is not linear, because as the space for thrusters becomes more limited, the propellant feed lines, cabling, etc., will increasingly become cumbersome while the thermal conditions and operating environment may also become more constraining.

Initially, some of the results may seem counterintuitive; a single NEXT thruster can outperform a single HiVHAC thruster, but two NEXT thrusters cannot outperform a NEXT and a HiVHAC thruster. There are several factors that come into play for this particular mission. For this DRM, the power level is only $10 \mathrm{~kW}$, so two NEXT thrusters cannot be fully utilized. The HiVHAC has a lower and more efficient minimum power operation, and the hybrid system provides a higher thrust-to-weight ratio for the spacecraft.

It is also worth noting that this analysis was carried out using either maximum thrust or maximum specific impulse setting throughout the mission. It may prove to be the case that operating the thrusters at maximum thrust only for the short duration of the plane change and operating the thrusters at higher Isp for the rest of the mission will result in higher performance. Analysis of segmented missions for optimal operating conditions has not been done. 


\section{Conclusions}

The use of hybrid electric propulsion systems is not an optimal solution for long term propulsion needs. Taking advantage of the redeeming attributes of both gridded ion and Hall systems is appealing because there is no single IPS that can meet the entire needs of the science community. The concept of a hybrid system will only remain appealing until an IPS can be built with higher thrust-to-power ratios with a significant increase in lifetime capability. The results for the Advanced HiVHAC thruster hint at this conclusion, and a lower sputter rate gridded ion thruster will likely show similar advantages. For large flagship missions, a single homogenous IPS could be built within the time and budget of a mission, but smaller competed missions can only propose systems that have been sufficiently demonstrated prior to Phase B. ${ }^{15}$ Unfortunately, new electric propulsion technology often requires extensive development and life testing with a very low opportunity for flight limiting opportunities for infusion.

The author does not believe that a hybrid system is an optimal IPS, but that mission planners should not be restricted to homogenous systems, sometimes proposing impractical numbers of thrusters to meet mission objectives without considering unconventional IPS options. A hybrid ion propulsion system can improve mission performance to achieve a desired specific impulse, better utilize the available power, achieve better lifetimes, reduce mission time, reduce IPS complexity, and/or reduce mission cost.

\section{Future Developments}

The HiVHAC thruster program is one step closer to a single thruster that can meet the majority of the needs of the user community. A successful advanced HiVHAC thruster will have the ability to operate at a wide range of thrust-to-power ratios and with suitable lifetimes. The HiVHAC will still be limited in some cases, because the thruster must scale power with voltage which correlates to specific impulse. The Hall thruster will not be able to operate at full power and low specific impulse like the BPT-4000.

Both JPL and GRC have pursued the use of lower sputter yield materials for gridded ion thrusters that can potentially extend thruster grid life by an order of magnitude. ${ }^{16,17}$ The Japanese program has demonstrated success using carbon based optics. ${ }^{18}$ GRC has also operated the NEXT thruster at several conditions outside of the baseline throttle curve. ${ }^{19}$ The NEXT thruster has demonstrated that it can operate at a much broader range of thrust-to-power with some negative life consequences. A NEXT thruster with carbon based optics may provide a single thruster flexible enough to meet near all of the user community's needs.

\section{Acknowledgments}

The work described in this paper was funded in whole or in part by the In-Space Propulsion Technology Program, which is managed by NASA's Science Mission Directorate in Washington, D.C., and implemented by the In-Space Propulsion Technology Project at Marshall Space Flight Center in Huntsville, AL. The program objective is to develop in-space propulsion technologies that can enable or benefit near and mid-term NASA space science missions by significantly reducing cost, mass or travel times. 


\section{References}

'Patterson, M. J., "Low-Isp Derated Ion Thruster Operation," AIAA-1992-3203.

${ }^{2}$ Peterson, P. Y., et al., "The Performance and Wear Characterization of a High-Power High-Isp NASA Hall Thruster," AIAA-2005-4243, Tucson, AZ, July 2005.

${ }^{3}$ Randolph, T. M., "The Prometheus 1 Spacecraft Preliminary Electric Propulsion System Design," AIAA-20053889, Tucson, AZ, July 2005.

${ }^{4}$ Baggett, R. M., et al., "In-Space Propulsion Solar Electric Propulsion Program Overview of 2006," AIAA-20064463, Sacramento, CA, July 2006.

${ }^{5}$ De Grys, K., et al., "BPT-4000 Multi-Mode 4.5 kW Hall Thruster Qualification Status," AIAA-2003-4552, Huntsville, AL, July 2003

${ }^{6}$ Frisbee, R. H., and Mikellides, I. G., "The Nuclear-Electric Pulsed Inductive Thruster (NuPIT): Mission Analysis for Prometheus," AIAA-2005-3892, Tucson, AZ, July 2005.

7 Adams, Robert B., et al., "Nuclear Electric Propulsion Evolution Study," NASA MSFC Internal, July 13, 2004.

${ }^{8}$ Cupples, M., Coverstone V., and Woo, B., "Application of Solar Electric Propulsion to a Comet Surface Sảmple Return Mission," AIAA-2004-3804, Fort Lauderdale, FL, July 2004.

${ }^{9}$ Witzberger, K. E., "Solar Electric Propulsion for Primitive Body Science Missions," JANNAF Conference, December 2005.

${ }^{10}$ Rayman, M. D., et al., 'Dawn: A Mission in Development for Exploration of Main Belt Asteroids Vesta and Ceres," 55 $5^{\text {th }}$ International Astronautical Congress, Vancouver, CA, October 2004.

${ }^{11}$ Brophy, J., "Preliminary Dawn IPS Lessons Learned," Briefing to ISP PE, September 9, 2005.

${ }^{12}$ Oh, D. Y., "Evaluation of Solar Electric Propulsion Technologies for Discovery Class Missions," AIAA-20054270, Tucson, AZ, July 2005.

${ }^{13}$ Williams, J. D., "Solar Electric Propulsion Technology Assessment Group Final Report," NASA MSFC ISPTSEP-06-101, February 24, 2006.

${ }^{14}$ Woodcock, G. R., and Dankanich, J. W., "Application of Solar-Electric Propulsion to Robotic and Human Missions in Near-Earth Space," AIAA-2006-4464, Sacramento, CA, July 2006.

15 "Announcement of Opportunity - Discovery Program 2006 and Missions of Opportunity," NASA NNH06ZDA001O, January 2, 2006.

${ }^{16}$ Snyder J., Brophy, J., Goebel, D., and Beatty, J., "Development and Testing of Carbon-Based Ion Optics for 30cm Ion Thrusters," AIAA-2003-4716, Huntsville, AL, July 2003.

${ }^{17}$ Haag, T., and Soulas, G., "Performance of $30 \mathrm{~cm}$ Pyrolytic-Graphite Ion Thruster Optics," AIAA-2003-4557, Huntsville, AL, July 2003.

${ }^{18}$ Funaki, I., et al., "Verification Tests of Carbon-Carbon Composite Grids for Microwave Discharge Ion Thruster," Journal of Propulsion and Power, Vol. 18, No. 1, 2002.

${ }^{19}$ Patterson, M. J., "NEXT Study of Thruster Extended Performance (NEXT STEP)," AIAA-2006-4464, Sacramento, CA, July 2006. 
M09-0144-Presentation

\section{Mission Benefits of Gridgled lon and Hall Thruster Hybrjol Propulsion Systems}

In Space Propulsion Technology Project NASA Marshall Space Flight Center Gray Research Inc. John Dankanich \& Tara Polsgrove $42^{\text {nd }}$ AIAA Joint Propulsion Conference July 9 - 12, 2006 
ISPT Project performs numerous mission studies that show significant benefits to technologies prior to investment. Technologies are almost always rated based on how they perform compared to other investments or existing systems but rarely on how they can improve similar systems.

$>$ IISTP - Several primary propulsion concepts rated against one another

$>$ Refocus - NEXT compared to NSTAR, Enhanced NSTAR, Low Power Hall

Synergistic relationship between technologies can lead to significant benefits. This is common practice for unrelated technologies.

$>$ EP/Aerocapture - Reference Mission to Neptune could not be performed with chemical or chemical/aerocapture propulsion, possibly electric. Mission enabled by SEP/Aerocapture.

$>$ SRTG/Long-life Hall - Enables deep-space small-body capture

Currently, the projected flight rate of NASA electrical propulsion systems is less than two missions per decade. This gives little opportunity for technology infusion of new primary propulsion systems. Also, competitive Discovery and New Frontiers class missions do not provide the budget or schedule to develop new mission specific primary propulsion.

What can be done with what we have?

What can add primary propulsion flexibility? 


\section{Introduction}

In the near term, there are two primary electric propulsion technologies suitable for NASA science missions, Hall thrusters and gridded ion thrusters.

Hall Thrusters

Higher Efficiency at Low Power

Higher thrust-to-power

Lower Thruster Cost

Lower PPU Cost
Gridded Ion Thrusters

Higher Efficiency at High Power

Higher specific impulse

Higher Throughput

Lower Specific Mass

\section{Past studies major conclusions:}

$>$ Gridded ion thrusters can benefit from higher thrust - lower $I_{s p}$ operation

$>$ A Hall thruster would be ideal for low cost missions if the life were greatly extended

$>$ The best thruster is one that can best utilize the available solar array power

Methods to achieve SEP requirements:

$>$ Using several gridded ion thrusters to achieve necessary thrust (6+1 CSSR, JIMO, etc.)

$>$ Using several Hall thrusters to meet necessary throughput

$>$ Increase B.O.L. solar array power

\section{Hybrid Hall and Gridded Ion Propulsion Systems}




\section{Thruster Options}

Limited the scope to include NASA existing or development thrusters, in addition to the commercial BPT-4000. At the time, these were the only thrusters receiving investment by ISPT.

\begin{tabular}{|c|c|c|c|c|}
\cline { 2 - 5 } \multicolumn{1}{c|}{} & NSTAR & NEXT & HIVHAC & BPT-4000 \\
\hline Max. Input Power (kW) & 2.3 & 6.9 & 3.6 & 4.5 \\
\hline Throttle Range & $4.8: 1$ & $12.6: 1$ & $12: 1$ & $4: 1$ \\
\hline Specific Impulse (s) & 3,100 & 4,170 & 2750 & 1983 \\
\hline Thrust (mN) & 94 & 236.4 & 150.7 & 282 \\
\hline Efficiency at Full Power & 0.6 & 0.7 & 0.57 & 0.57 \\
\hline Thrust-to-Power (mN/kW) & 40 & 34 & 41.9 & 63 \\
\hline Throughput (kg) & 157 & $>300^{*}$ & $>150^{*}$ & $>172^{*}$ \\
\hline Specific Mass (kg/kW) & 3.6 & 1.9 & 2.4 & 2.73 \\
\hline
\end{tabular}

Several other Hall thrusters and the commercial XIPS may also have applicability to SMD electric propulsion missions.
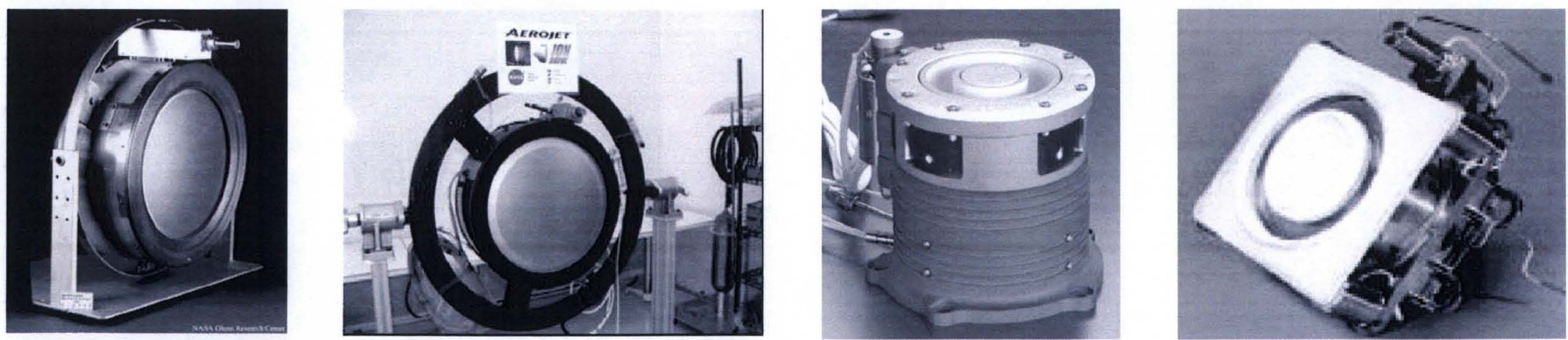


\section{Operational Scenarios}

Simultaneous Operation - Higher throughput than Hall alone, higher thrust-to-power ratio than gridded ion alone.

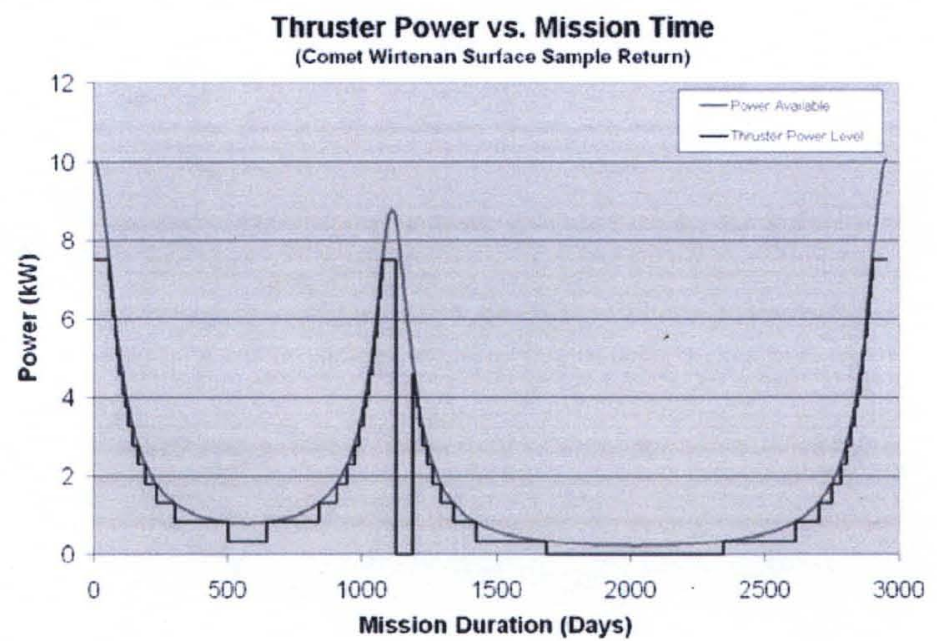

Thrust-to-Power of Various Thrusters

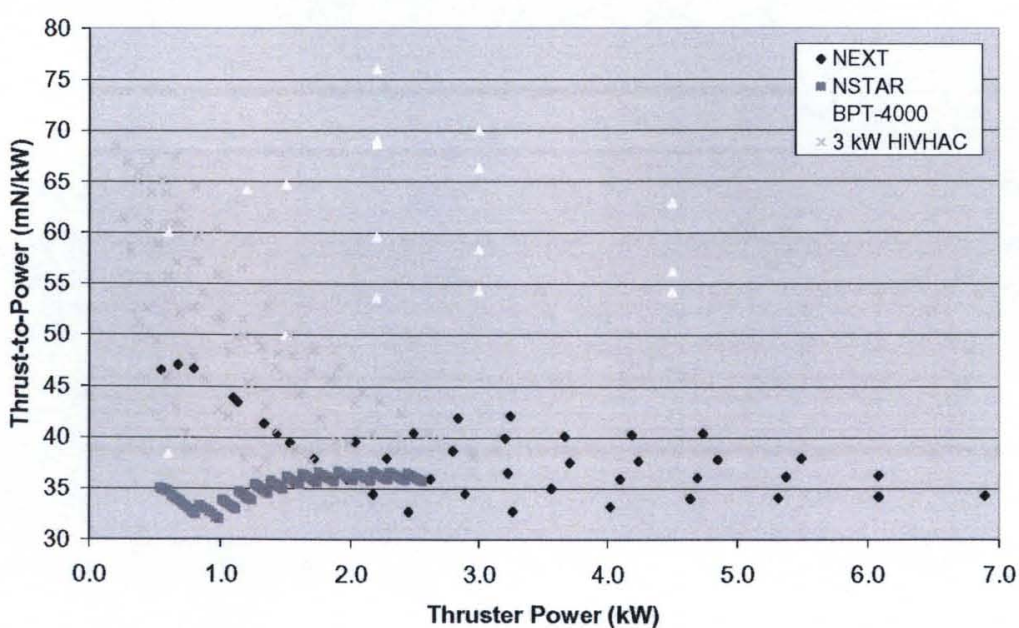

Thrust-to-Power of Hybrid Thrusters

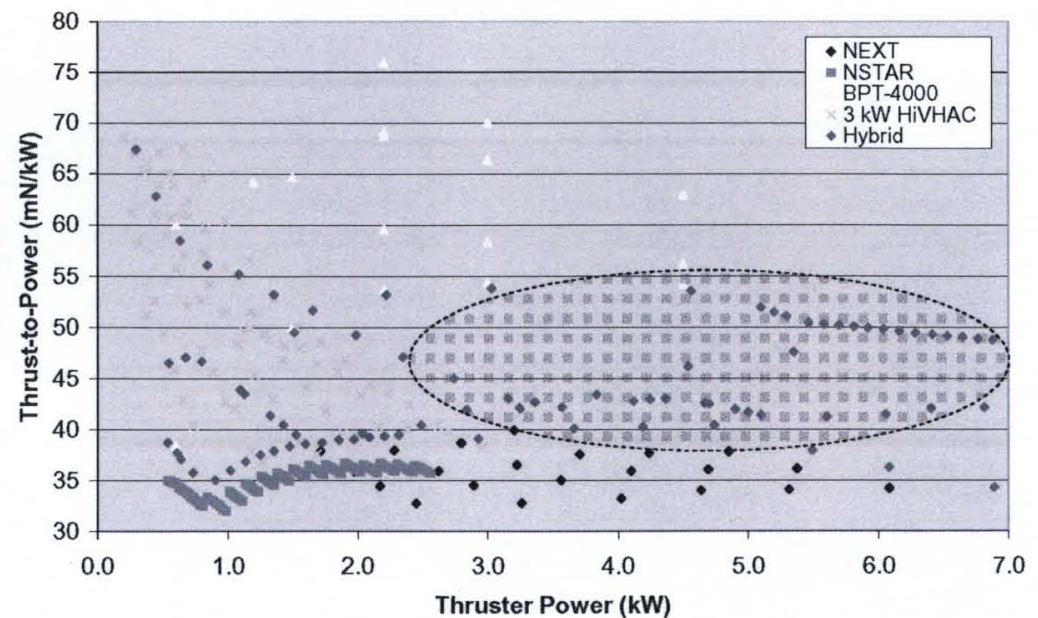




\section{Operational Scenarios}

\section{Low Power/High Power - One thruster for low power with another}

thruster for high power.

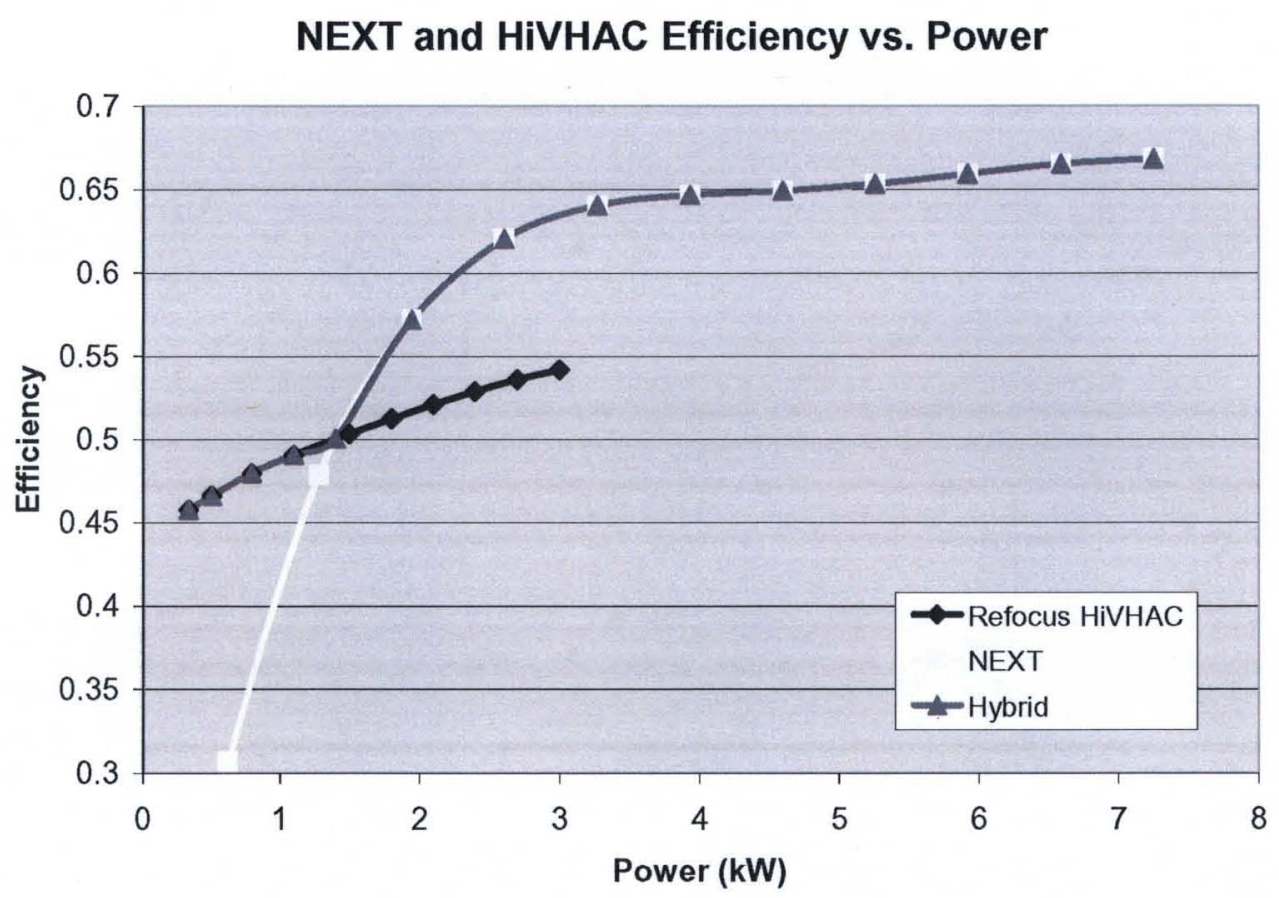

Combining thrusters can significantly increase the efficiency over large throttle ranges. 


\section{Operational Scenarios}

Staged Operation - Higher thrust for earth escape and higher specific impulse for interplanetary transfer.

Low thrust missions have a tendency to optimize to high escape energies $>10 \mathrm{~km}^{2} / \mathrm{s}^{2}$

Prior to optimal escape energy, the mission leverages the high thrust of the launch vehicle upper stage.

There is another scenario where launched to an escape energy $<-10 \mathrm{~km}^{2} / \mathrm{s}^{2}$ that will leverage the higher performance of an electric propulsion system

Electric propulsion systems within the gravity well optimize to lower specific impulses

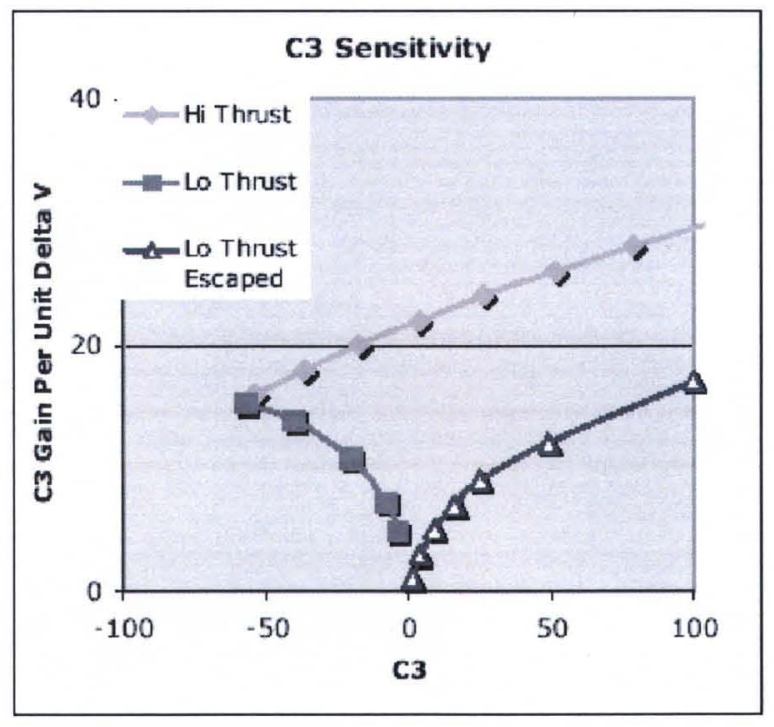
than those desired for interplanetary transfer.

Staged approach briefly considered for JIMO mission with gridded ion thrusters for interplanetary transfer and Hall for faster transfer in the high radiation environment of Jupiter. 


\section{Thrust-to-Power}

There is a misconception outside the low-thrust community that higher specific impulse is always better. This is based on the rocket equation and its general application to high thrust and high jet power systems.

$$
\frac{m_{0}}{m_{1}}=e^{\frac{\Delta V}{g l s p}}
$$

For a given power, there is a trade between thrust and specific impulse.

$$
P=\frac{g\left(F I_{s p}\right)}{2 \eta}
$$

There are scenarios that optimize to higher thrust and lower specific impulses from effects on $\Delta \mathrm{V}$, such as plane change and gravity losses, in addition to trip time limitations and orbital alignment constraints.
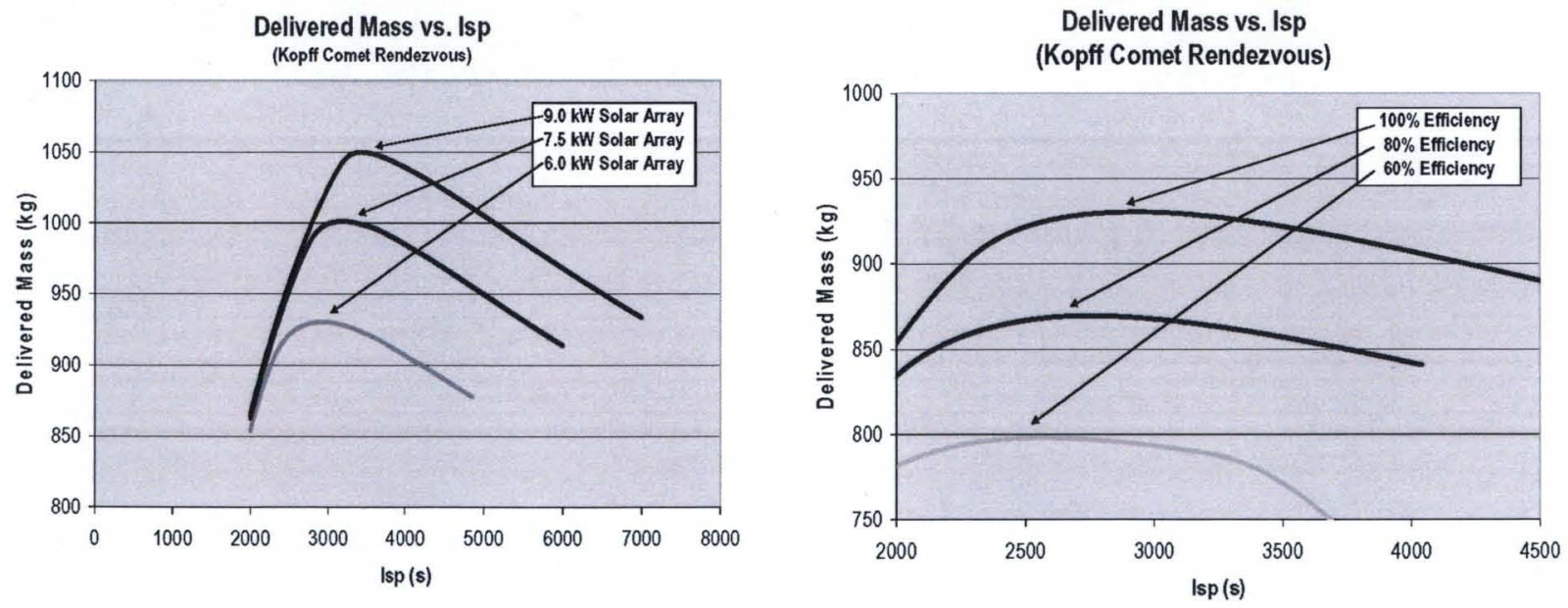


\section{Power Utilization}

Performance of electric propulsion systems is very sensitive to the ability to operate across large throttle ranges. Also, high power ion propulsion systems have a large decrease in performance as they approach their minimum input power limit.
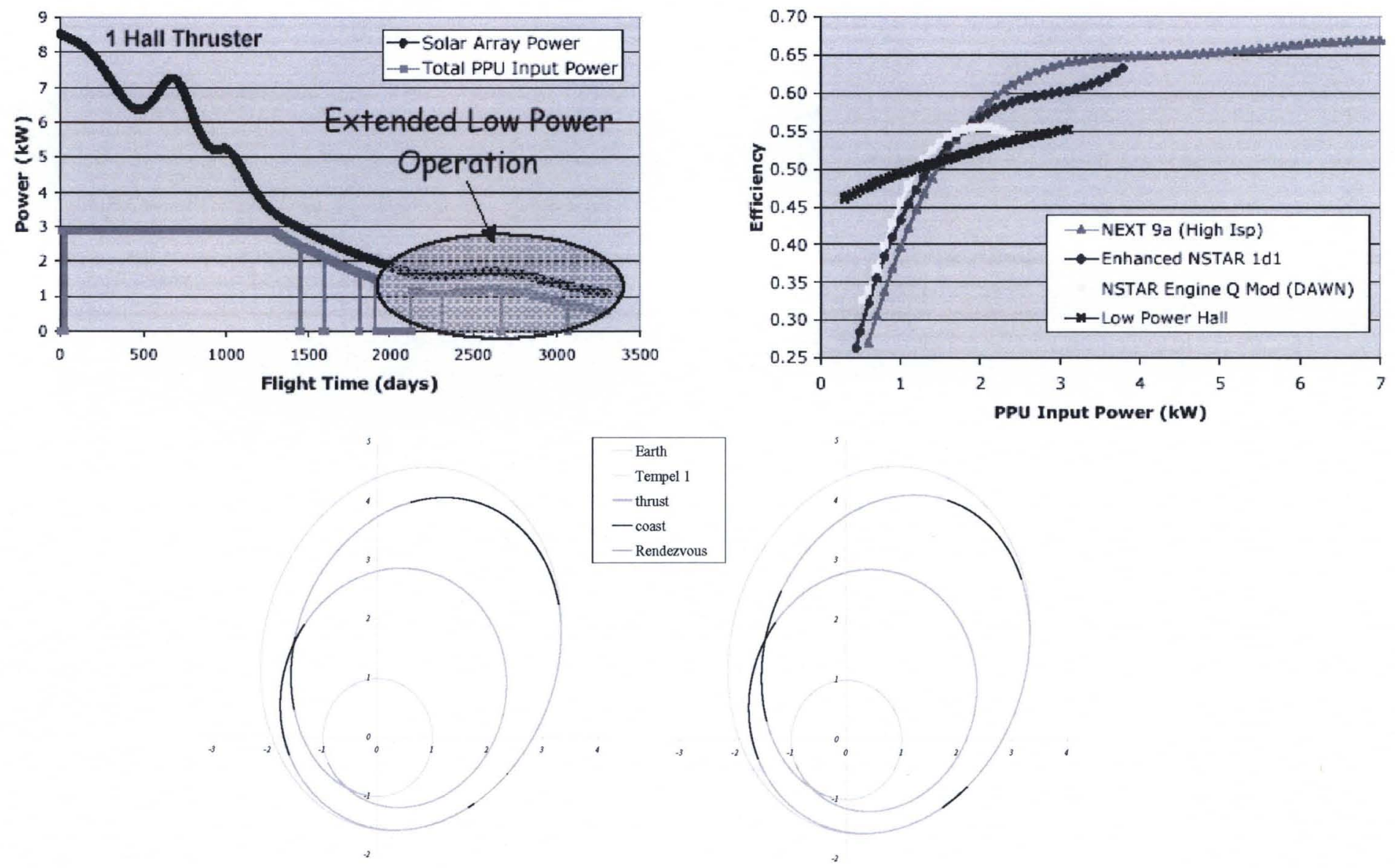


\section{Analysis Assumptions}

\begin{tabular}{|l|c|c|c|c|}
\cline { 2 - 4 } \multicolumn{1}{c|}{} & NSTAR & NEXT & HIVHAC & BPT-4000 \\
\hline Mass per Thruster (kg) & 8.2 & 12.7 & 9 & 12.3 \\
\hline Mass per PPU/DCIU (kg) & 15.9 & 36.6 & 10.5 & 12.5 \\
\hline Mass per Gimbal (kg) & 5.25 & 5.98 & 5 & 6 \\
\hline Fixed Mass XFS (kg) & 2.2 & 2.2 & 4 & 4 \\
\hline XFS Mass per Thruster (kg) & 4.1 & 4.1 & 1 & 1 \\
\hline Nav. \& Traj. Errors & $5.0 \%$ & $5.0 \%$ & $5.0 \%$ & $5.0 \%$ \\
\hline Residuals & $3.6 \%$ & $3.6 \%$ & $3.6 \%$ & $3.6 \%$ \\
\hline Tank Fraction & $4.50 \%$ & $4.50 \%$ & $4.50 \%$ & $4.50 \%$ \\
\hline
\end{tabular}

- Minimum number of thrusters to perform the mission.

- Additional thrusters as necessary to meet life requirements plus one for redundancy.

- Number of simultaneous thrusters to maximize net delivered mass.

- Hybrid redundancy used a $2+2$ configuration with one redundant thruster of each type.

-There was no consideration as to how many thrusters can realistically fit on a spacecraft.

- Hybrid thrusters compared both as simultaneously operating and maximum efficiency curve.

- Mass contingency of $30 \%$ on development hardware and $10 \%$ on heritage hardware. 
NASA's New Frontiers program includes multiple missions, with CSSR as the best candidate for an electric propulsion mission. CSSR missions have been studied in depth for Temple 1 and the DRM to the Comet Wirtenan.

Requires plane change to meet entry velocity requirement.

Without allowing additional revolutions of the sun, relatively large $\Delta \mathrm{V}$ required in a short period of time.

Wirtenan CSSR Delivered Mass vs. Isp
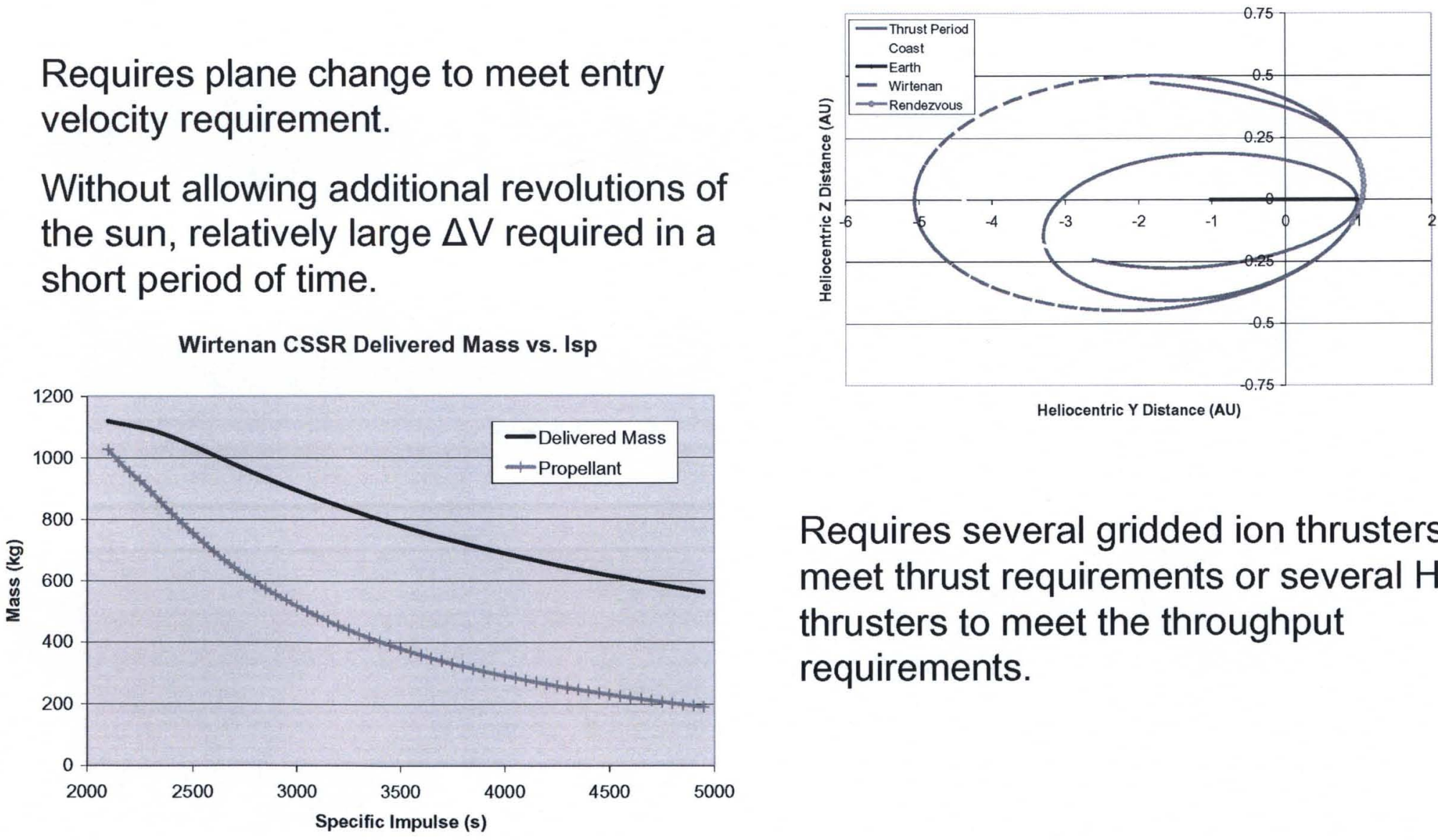

Requires several gridded ion thrusters to meet thrust requirements or several Hall thrusters to meet the throughput requirements. 


\section{CSSR Results}

\section{Relative Performance of IPS}

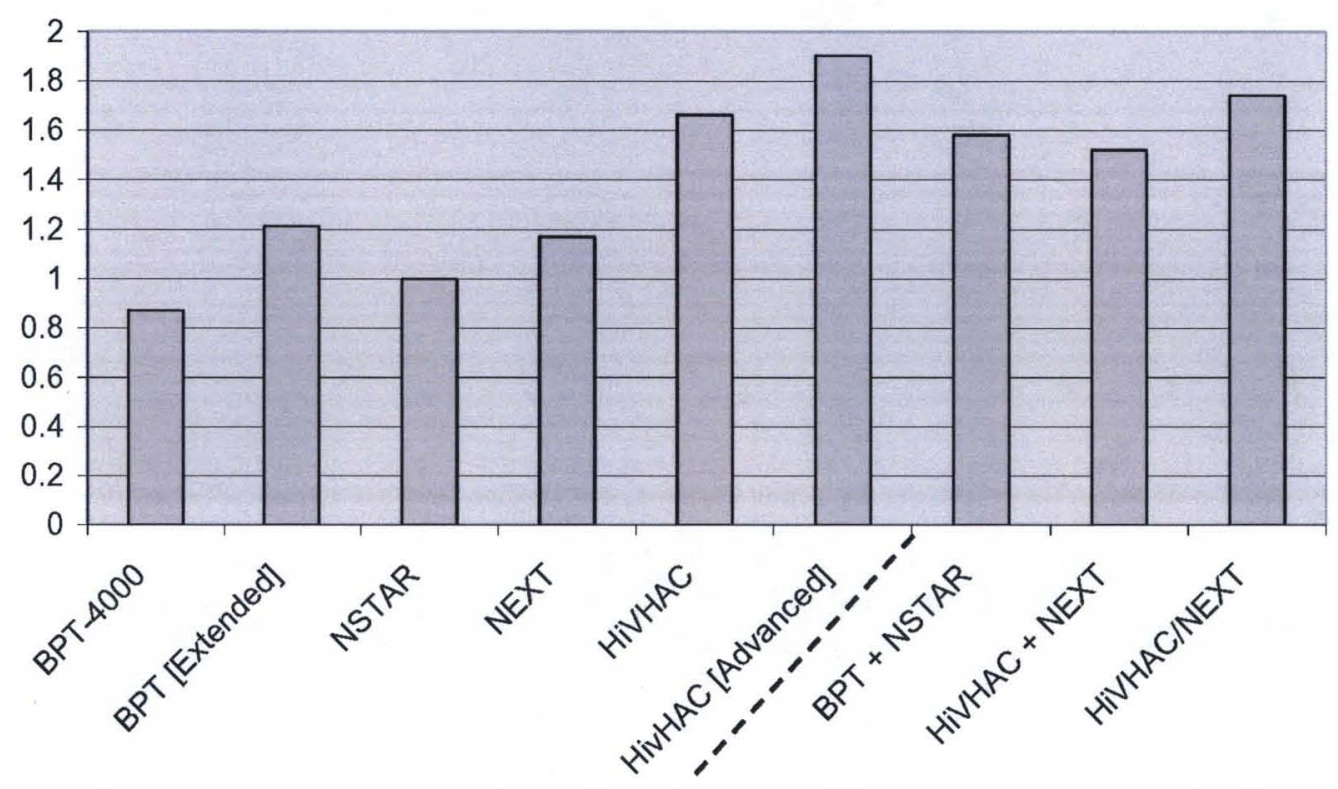

$>$ Hall thrusters are limited by life

$>$ Advanced HiVHAC highest performance IPS

$>$ Hybrid systems outperformed all but low TRL thruster

$>$ Hybrid system with EXISTING hardware outperformed SOA homogenous system by $60 \%$ 


\section{Dawn}

NASA's Dawn mission is a Discovery class mission and the first science mission to use primary electric propulsion. The spacecraft will be the first to orbit two bodies in the same mission.

\begin{tabular}{|c|c|c|c|c|c|}
\hline & Single NSTAR & $\begin{array}{c}\text { Single NSTAR } \\
\text { Enhanced }\end{array}$ & $\begin{array}{l}\text { NEXT (High } \\
\text { Thrust) }\end{array}$ & Low Power Hall & $\begin{array}{c}\text { Low Power Hall } \\
\text { (small Array) }\end{array}$ \\
\hline \multicolumn{6}{|l|}{ Mission } \\
\hline $\begin{array}{l}\text { Launch Vehicle } \\
\text { Trip Time (yrs.) } \\
\text { C3(km2/s2) } \\
\text { Power (1 AU, BOL, kW) }\end{array}$ & $\begin{array}{c}\text { Delta } 2925 \mathrm{H} \\
9.00 \\
7.3 \\
8.67\end{array}$ & $\begin{array}{c}\text { Delta } 2925 \mathrm{H} \\
9.00 \\
6.8 \\
8.67\end{array}$ & $\begin{array}{c}\text { Delta } 2925 \mathrm{H} \\
9.00 \\
0.0 \\
8.67\end{array}$ & $\begin{array}{c}\text { Delta } 2925 \mathrm{H} \\
9.00 \\
0.0 \\
8.67\end{array}$ & $\begin{array}{c}\text { Delta } 2925 \mathrm{H} \\
9.00 \\
0.0 \\
7.00\end{array}$ \\
\hline $\begin{array}{r}\text { Payload Mass Performance }(\mathrm{kg}) \\
\text { Launch Mass }(\mathrm{kg}) \\
\text { Xenon Propellant Throughput }(\mathrm{kg}) \\
\text { Net Trajectory Mass Capability }(\mathrm{kg}) \\
\text { Propulsion Subsystem Mass }(\mathrm{kg})\end{array}$ & $\begin{array}{c}702 \\
1294 \\
385 \\
882 \\
180\end{array}$ & $\begin{array}{c}726 \\
1307 \\
395 \\
888 \\
162 \\
\end{array}$ & $\begin{array}{c}738 \\
1509 \\
527 \\
958 \\
220 \\
\end{array}$ & $\begin{array}{c}800 \\
1509 \\
537 \\
942 \\
142 \\
\end{array}$ & $\begin{array}{c}703 \\
1508 \\
597 \\
855 \\
152 \\
\end{array}$ \\
\hline
\end{tabular}

* Performed by Steven Williams for Refocus Studies

Ideal thruster for Dawn is a higher thrust longer life thruster

Due to redundancy required a $2+2$ simultaneously operating or maximum efficiency hybrid does not have a significant improvement in performance.

\section{Using a staged EP system can trade trip time for performance.}




\section{Dawn Results}

From LEO, 700 days yields $\sim 250 \%$ net delivered mass

- Dawn Science < 6\% spacecraft mass

- Radiation risk

From elliptical launch, 180 days yields $\sim 150 \%$ net delivered mass

Higher thrust engines can mitigate missed thrust periods if propellant is available

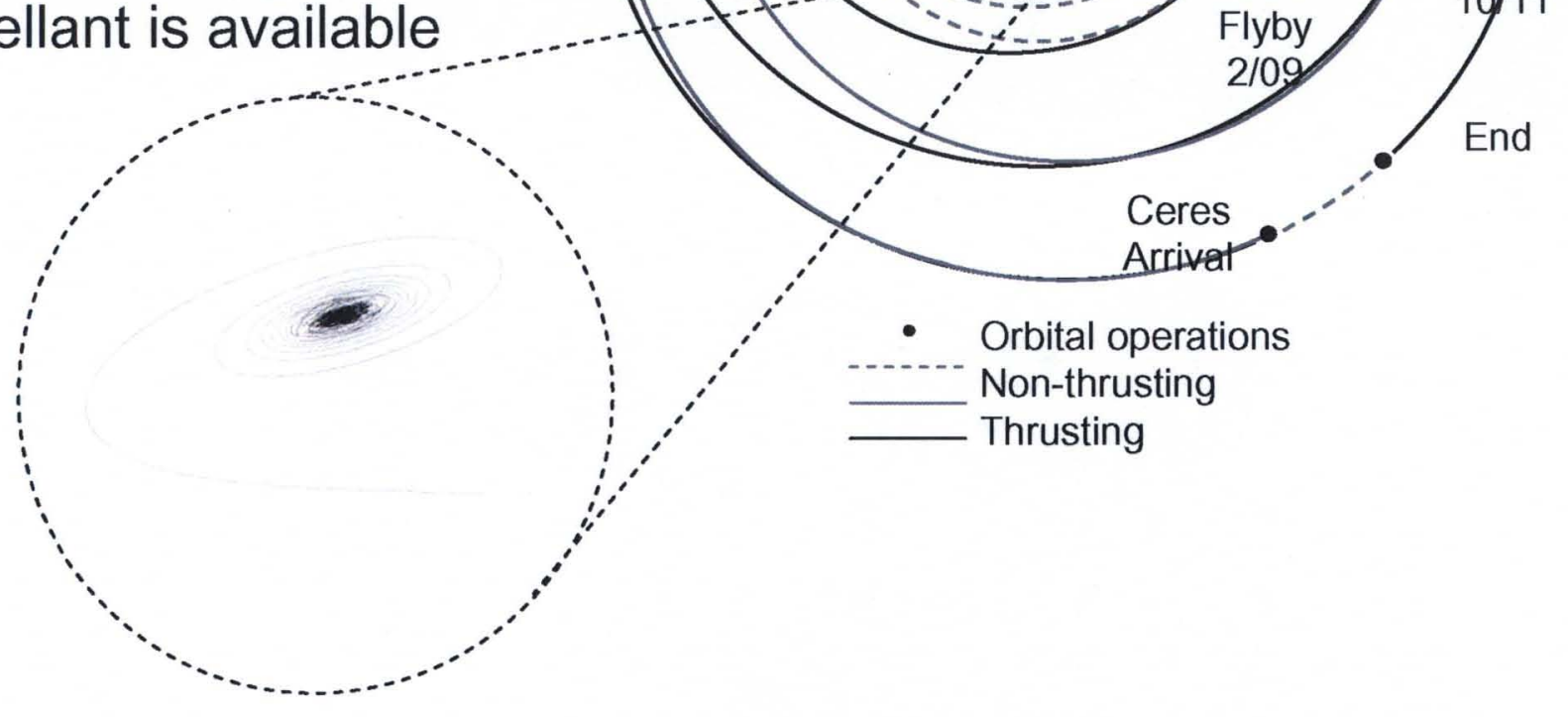




\section{Concerns}

- Part spares/procurements

- Spacecraft integration

- Failure mode trajectory analysis 


\section{Conclusions}

- The use of hybrid electric propulsion systems may not be an optimal solution for long term propulsion needs, but can significantly increase the performance capability of existing homogenous ion propulsion systems without any new technology development.

- A higher thrust-to-power gridded ion engine can significantly improve performance over SOA thrusters.

- A longer life Hall thruster can significantly improve performance over SOA thrusters.

- Mission planners should consider unconventional IPS options.

- A thruster to assist existing ion propulsion systems may prove more beneficial than another stand-alone development. 


\section{Future Work}

- Examine Inter-planetary Missions

- Will require additional strings near Earth to use available power deeper in mission

- Increasing power profiles may optimize to higher specific impulse than steep decreasing power profiles

- Look at small chemical (RCS?) as EP assist

- Deep space plane changes

- DoD BAA

- Mass and lifetime effects of bi-modal thrusters

- Hall thruster than can operate at either high thrust or high Isp

- NEXT extended throttle table performance 


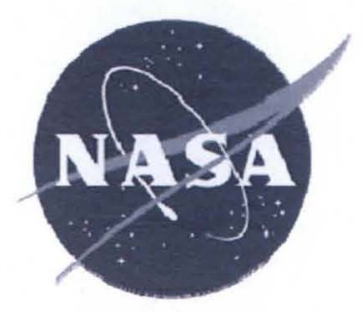

www.nasa.gov

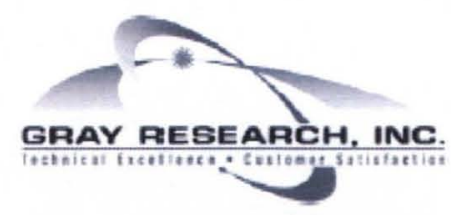

www.gray-research.com 


\section{Acknowledgments}

The work described in this paper was funded in whole or in part by the InSpace Propulsion Technology Program, which is managed by NASA's Science Mission Directorate in Washington, D.C., and implemented by the In-Space Propulsion Technology Project at Marshall Space Flight Center in Huntsville, AL. The program objective is to develop in-space propulsion technologies that can enable or benefit near and mid-term NASA space science missions by significantly reducing cost, mass or travel times. The author would like to especially thank Carl Sauer for his assistance with trajectory optimization. 


\section{Backup Slides}




\section{Backup}

Table 3: Homogenous IPS performance comparison.

\begin{tabular}{|c|c|c|c|c|c|c|}
\hline Thruster & NEXT & HiVHAC & $\begin{array}{l}\text { HIVHAC } \\
\text { (Advanced) }\end{array}$ & NSTAR & BPT -4000 & $\begin{array}{l}\text { BPT-4000 } \\
\text { [Extended] }\end{array}$ \\
\hline \# of Operating Thrusters & 2 & $\overline{3}$ & $\overline{3}$ & 3 & 2 & 2 \\
\hline \# of Spare Thrusters for Life & 0 & 3 & 0 & 0 & 6 & 2 \\
\hline \# of Spare Thrusters for Redundanc & 1 & 1 & 1 & 1 & 1 & 1 \\
\hline Total Thrusters & $3(2+1)$ & $7(3+4)$ & $4(3+1)$ & $4(3+1)$ & $9(2+7)$ & $5(2+3)$ \\
\hline Array Power (kW @ 1 AU B.O.L.) & 10 & 10 & 10 & 10 & 10 & 10 \\
\hline Launch Vehicle & Atlas 401 & Atlas 401 & Atlas 401 & Atlas 401 & Atlas 401 & Atlas 401 \\
\hline Trip Time (yrs) & 8 & 8 & 8 & 8 & 8 & 8 \\
\hline $\mathrm{C} 3\left(\mathrm{~km}^{2} / \mathrm{s}^{2}\right)$ & 38.64 & 28.12 & 28.12 & 48.2 & 24.7 & 24.7 \\
\hline $\mathrm{m0}(\mathrm{kg})$ & 1511.4 & 1936.7 & 1936.7 & 1168 & 2094.2 & 2094.2 \\
\hline Mp - Required Throughput (kg) & 525.9 & 775.1 & 775.1 & 375.2 & 1124.9 & 1124.9 \\
\hline Throughput Contingency (kg) & 42.6 & 62.8 & 62.8 & 62.8 & 91.1 & 91.1 \\
\hline Total Propellant (kg) & 568.5 & 837.9 & 837.9 & 438 & 1216 & 1216 \\
\hline Tank Mass (kg) & 25.6 & 37.7 & 37.7 & 19.7 & 54.7 & 54.7 \\
\hline IPS Drymass (kg) & 257.1 & 220.2 & 143.7 & 155.7 & 344.9 & 217.7 \\
\hline Drymass Contingency (kg) & 77.1 & 66.1 & 43.1 & 36 & 48 & 34.5 \\
\hline Total Wet Mass (kg) & 902.7 & 1124.2 & 1024.7 & 629.7 & 1608.9 & 1468.2 \\
\hline Mass Left at Comet (kg) & 125 & 125 & 125 & 125 & 125 & 125 \\
\hline Net Delivered Mass $(\mathbf{k g})^{k+k}$ & 483.7 & 687.5 & 787 & 413.3 & 360.3 & 501 \\
\hline
\end{tabular}

Table 4: Hybrid IPS performance comparison.

\begin{tabular}{|c|c|c|c|}
\hline Thruster & HiV / NEXT & HiV + NEXT & NSTAR+BPT \\
\hline \# of Operating Thrusters & $2(1,1)$ & $2(1,1)$ & $2(1,1)$ \\
\hline \# of Spare Thrusters for Life & $1^{*}$ & $1^{*}$ & $1^{*}$ \\
\hline \# of Spare Thrusters for Redundanc & $1^{*}$ & $1^{*}$ & $1^{*}$ \\
\hline \begin{tabular}{|l|} 
Total Thrusters \\
\end{tabular} & $4(2+2)$ & $4(2+2)$ & $4(2+2)$ \\
\hline Array Power (kW @1 AU B.O.L.) & 10 & 10 & 10 \\
\hline Launch Vehicle & Atlas 401 & Atlas 401 & Atlas 401 \\
\hline Trip Time (yrs) & 8.1 & 8 & 8 \\
\hline C3 $\left(\mathrm{km}^{2} / \mathrm{s}^{2}\right)$ & 34.83 & 37.62 & 37 \\
\hline $\mathrm{mo}(\mathrm{kg})$ & 1659.7 & 1550.7 & 1575.6 \\
\hline Mp - Required Throughput (kg) & 517.1 & 500.3 & 557.2 \\
\hline Throughput Contingency (kg) & 41.9 & 40.5 & 45.1 \\
\hline Total Propellant (kg) & 559 & 540.8 & 602.3 \\
\hline Tank Mass (kg) & 25.2 & 24.3 & 27.1 \\
\hline IPS Drymass (kg) & 197.2 & 197.2 & 159.8 \\
\hline Drymass Contingency (kg) & 59.1 & 59.1 & 34.7 \\
\hline Total Wet Mass (kg) & 815.3 & 797.1 & 796.8 \\
\hline Mass Left at Comet (kg) & 125 & 125 & 125 \\
\hline Net Delivered Mass $(\mathbf{k g})^{\star \star \star}$ & 719.4 & 628.6 & 653.8 \\
\hline
\end{tabular}




\section{References}

•Patterson, M. J., "Low-Isp Derated Ion Thruster Operation," AIAA-1992-3203.

•Peterson, P. Y., et al., "The Performance and Wear Characterization of a High-Power High-Isp NASA Hall Thruster," AIAA-2005-4243, Tucson, AZ, July 2005.

-Randolph, T. M., "The Prometheus 1 Spacecraft Preliminary Electric Propulsion System Design," AIAA-2005-3889, Tucson, AZ, July 2005. -Baggett, R. M., et al., "In-Space Propulsion Solar Electric Propulsion Program Overview of 2006," AIAA-2006-TBD, Sacramento, CA, July 2006.

-De Grys, K., et al., "BPT-4000 Multi-Mode 4.5 kW Hall Thruster Qualification Status," AIAA-2003-4552, Huntsville, AL, July 2003

-Frisbee, R. H., and Mikellides, I. G., "The Nuclear-Electric Pulsed Inductive Thruster (NuPIT): Mission Analysis for Prometheus," AIAA2005-3892, Tucson, AZ, July 2005.

-Adams, Robert B., et al., "Nuclear Electric Propulsion Evolution Study," NASA MSFC Internal, July 13, 2004.

-Cupples, M., Coverstone V., and Woo, B., "Application of Solar Electric Propulsion to a Comet Surface Sample Return Mission," AIAA2004-3804, Fort Lauderdale, FL, July 2004.

-Witzberger, K. E., "Solar Electric Propulsion for Primitive Body Science Missions," JANNAF Conference, December 2005.

-Rayman, M. D., et al., "Dawn: A Mission in Development for Exploration of Main Belt Asteroids Vesta and Ceres," 55th International

Astronautical Congress, Vancouver, CA, October 2004.

-Brophy, J., "Preliminary Dawn IPS Lessons Learned," Briefing to ISP PE, September 9, 2005.

-Oh, D. Y., "Evaluation of Solar Electric Propulsion Technologies for Discovery Class Missions," AIAA-2005-4270, Tucson, AZ, July 2005. -Williams, J. D., "Solar Electric Propulsion Technology Assessment Group Final Report," NASA MSFC ISPT-SEP-06-101, February 24, 2006.

-Woodcock, G. R., and Dankanich, J. W., "Application of Solar-Electric Propulsion to Robotic and Human Missions in Near-Earth Space," AIAA-2006-TBD, Sacramento, CA, July 2006.

-"Announcement of Opportunity - Discovery Program 2006 and Missions of Opportunity," NASA NNH06ZDA001O, January 2, 2006.

-Snyder J., Brophy, J., Goebel, D., and Beatty, J., "Development and Testing of Carbon-Based Ion Optics for 30-cm lon Thrusters," AIAA2003-4716, Huntsville, AL, July 2003.

•Haag, T., and Soulas, G., "Performance of $30 \mathrm{~cm}$ Pyrolytic-Graphite Ion Thruster Optics," AIAA-2003-4557, Huntsville, AL, July 2003.

-Funaki, I., et al., "Verification Tests of Carbon-Carbon Composite Grids for Microwave Discharge Ion Thruster," Journal of Propulsion and Power, Vol. 18, No. 1, 2002.

•Patterson, M. J., "NEXT Study of Thruster Extended Performance (NEXT STEP)," AIAA-2006-TBD, Sacramento, CA, July 2006. 